\title{
REVIEW ARTICLE OPEN Electrochemically driven conversion reaction in fluoride electrodes for energy storage devices
}

\author{
Chilin $\mathrm{Li}^{1}$, Keyi Chen ${ }^{1,2}$, Xuejun Zhou ${ }^{1}$ and Joachim Maier $\mathbb{B}^{3}$
}

Exploring electrochemically driven conversion reactions for the development of novel energy storage materials is an important topic as they can deliver higher energy densities than current Li-ion battery electrodes. Conversion-type fluorides promise particularly high energy densities by involving the light and small fluoride anion, and bond breaking can occur at relatively low Li activity (i.e., high cell voltage). Cells based on such electrodes may become competitors to other envisaged alternatives such as Lisulfur or Li-air systems with their many unsolved thermodynamic and kinetic problems. Relevant conversion reactions are typically multiphase redox reactions characterized by nucleation and growth processes along with pronounced interfacial and mass transport phenomena. Hence significant overpotentials and nonequilibrium reaction pathways are involved. In this review, we summarize recent findings in terms of phase evolution phenomena and mechanistic features of (oxy)fluorides at different redox stages during the conversion process, enabled by advanced characterization technologies and simulation methods. It can be concluded that well-designed nanostructured architectures are helpful in mitigating kinetic problems such as the usually pronounced voltage hysteresis. In this context, doping and open-framework strategies are useful. By these tools, simple materials that are unable to allow for substantial Li nonstoichiometry (e.g., by Li-insertable channels) may be turned into electroactive materials.

npj Computational Materials (2018)4:22 ; doi:10.1038/s41524-018-0079-6

\section{INTRODUCTION}

Higher energy density is required for energy storage devices, in particular for large-scale application in the electromobility market of the near future. For this purpose, Li metal batteries (LMBs) with Li metal as anode are receiving renewed attention after the shortlived research enthusiasm during 1970-1980. Later, the prevalence of LMBs was replaced by the advent of powerful Li-ion batteries (LIBs) offering a greater safety due to absence of $\mathrm{Li}$ dendrite growth. Owing to the progress in nanotechnology and in solid electrolyte research, there is hope that Li dendrite can be effectively suppressed and LMBs can be returned to., ${ }^{1,2} \mathrm{Li}$ metal has the highest theoretical capacity of $3860 \mathrm{mAh} / \mathrm{g}$ (one magnitude higher than the $372 \mathrm{mAh} / \mathrm{g}$ of graphite $\mathrm{C}$ or $\mathrm{LiC}_{6}$, the commercial anode for LIBs) and lowest redox potential (3.04 V vs. the standard hydrogen electrode). ${ }^{3}$ In order to match well with the high capacity of the metal Li anode, conversion cathodes with their large capacities are desired, resulting in the recent development of $\mathrm{Li}-\mathrm{S}$ and $\mathrm{Li}_{-} \mathrm{O}_{2}$ batteries. ${ }^{4}$ They can release a reversible capacity of more than $1000 \mathrm{mAh} / \mathrm{g}$ provided careful cathode designs are developed to, in particular, mitigate problems such as polysulfide dissolution for Li-S-induced and peroxideinduced side reaction for $\mathrm{Li}_{2} \mathrm{O}_{2}$. The dissolution problem in $\mathrm{Li}-\mathrm{S}$ batteries gives rise to shuttle effects and active material losses, and the side reaction problem in $\mathrm{Li}^{-} \mathrm{O}_{2}$ batteries to poor energy efficiency. To alleviate these issues, complex porous conductive networks are often resorted to in order to either spatially confine reaction products, or construct gas passage and catalyst bonding sites. ${ }^{4}$ However such non-active components lower the specific capacity of practical electrodes.

Alternative candidates for conversion cathodes are transition metal fluorides owing to their high theoretical voltage and multielectron transfer based on the reduction of transition metal cation to the neutral metal., ${ }^{5,6}$ Compared with oxide and sulfide counterparts, the high ionicity of $\mathrm{M}-\mathrm{F}$ bonding favors higher reaction voltage frequently, however, at the cost of lower electronic conductivity and-not independently from this-of a smaller solubility range. Different from $\mathrm{Li}-\mathrm{S}$ and $\mathrm{Li}_{-} \mathrm{O}_{2}$ systems, fluorides usually undergo solid-solid conversion reaction. Notwithstanding the interfacial and diffusional problems that conversion reactions bring about, they may have the advantage that admixtures of additional current collectors can be minimized if the spatial distribution of pristine fluoride nanoparticles and conversion (intermediate) products (e.g., M and LiF) is optimized. ${ }^{7,8}$ Such optimization critically depends on the interconnection of product $M$ nanodomains forming a built-in electronconductive percolating network; ${ }^{9}$ the other product LiF is neither a perceptible electron nor ion conductor. The ion conductivity is particularly bad if it is crystallized. However the electrochemical process can lead to amorphization, which seems beneficial with respect to mass transport issues. ${ }^{10}$ Electrochemistry-driven solid-solid phase transformation remarkably influences the pathway of $\mathrm{Li} / \mathrm{Na}$ transport and storage in fluoride lattices. Grain boundaries and intra-grain multiphase interfaces should not markedly hinder the transport of the mobile carriers. In practice, however, even for the insertion reaction without breaking $M-F$ bonding, the occurrence of multiphase reactions is a problem for

\footnotetext{
${ }^{1}$ State Key Laboratory of High Performance Ceramics and Superfine Microstructure, Shanghai Institute of Ceramics Chinese Academy of Sciences Shanghai 200050, China; ${ }^{2}$ University of Chinese Academy of Sciences, Beijing 100039, China and ${ }^{3}$ Max Planck Institute for Solid State Research, Heisenbergstraße 1, D-70569 Stuttgart, Germany Correspondence: Chilin Li (chilinli@mail.sic.ac.cn)
}

Received: 2 November 2017 Revised: 12 March 2018 Accepted: 30 March 2018 Published online: 23 April 2018 
achieving high-rate performance. ${ }^{11}$ Conversion reactions are characterized by interface formation/annihilation and hence by severe charge transfer and transport issues, all critically depending on the phase distribution. Therefore, investigating, simulating, and possibly tuning the microstructure evolution is of significant importance.

Recently, anion doping (e.g., O-doping in $\mathrm{FeF}_{2}$ ) was shown to significantly enhance the electron conductivity while the original crystalline structure was preserved. ${ }^{12}$ Another strategy is to introduce open frameworks (e.g., introduction of bronze and pyrochlore phases) and hence spacious ion channels and extended solid-solution reaction zone; ${ }^{13,14}$ these modifications of the ligand units or of the way how they are linked are expected to further complicate the microstructure evolution and phase transformation pathway in conversion fluorides.

Here, we summarize the recent progress on electrochemistrydriven phase transformation in conversion fluorides for Li-based and Na-based batteries and outline the corresponding phase transformation scenarios as available from electrochemical and microstructural characterizations, as well as from theoretical simulation. We do not intend to go into detail with respect to performance or synthesis. Rather we wish to set out characteristic features. As far as characterization is concerned, we refer to results stemming from physical characterizations such as transmission electron microscopy (TEM), electron energy-loss spectroscopy (EELS), solid nuclear magnetic resonance (NMR), X-ray absorption spectroscopy (XAS), pair distribution function (PDF) analysis, and transmission X-ray microscopy (TXM). ${ }^{9,15,16}$ Routine tools such as X-ray diffraction (XRD) are not appropriate for obtaining information on poorly crystallized conversion products. Amorphization or nanosizing of conversion products is often met, and it increases the difficulty of elaborate and quantitative characterization. ${ }^{17}$

In this review, we first describe the conversion reaction mechanism of iron-based fluorides $\left(\mathrm{FeF}_{2}\right.$ and $\left.\mathrm{FeF}_{3}\right)$, the most popular and commercially available conversion salts. Then we discuss the impact of compositional modifications (mixed-anion effects, water incorporation within the open-framework strategy) on the performance of the conversion mechanism. Hereafter, we address the use and usefulness of non-iron fluorides. In particular, we describe the mixed cation effect in Cu-based ternary fluorides as well as the electrochemical splitting of LiF with the help of lowvalence-state fluorides or oxides.

\section{CONVERSION REACTION IN FEF $\boldsymbol{X}$ ELECTRODES}

In 1997, Arai et al. ${ }^{18}$ firstly introduced fluorides as potential insertion-type cathode materials in view of a larger theoretical capacity (e.g., $237 \mathrm{mAh} / \mathrm{g}$ for $3 \mathrm{~V}$ region $\mathrm{FeF}_{3}$ based on oneelectron transfer) than that of $\mathrm{LiFePO}_{4}(170 \mathrm{mAh} / \mathrm{g})$. However, even the most electroactive $\mathrm{FeF}_{3}$ material only released a reversible capacity of $80 \mathrm{mAh} / \mathrm{g}$. Later, Badway et al. ${ }^{11,19}$ fabricated $\mathrm{FeF}_{3}-\mathrm{C}$ nanocomposites by ball milling commercially available $\mathrm{ReO}_{3}$-type $\mathrm{FeF}_{3}$ and activated carbon (15 wt\%). Notwithstanding the various reaction stages $\mathrm{FeF}_{3}$ exhibits a voltage that is higher by $1-2 \mathrm{~V}$ than $\mathrm{Fe}_{2} \mathrm{O}_{3}$ owing to the induction effect of fluorine on the metal-nonmetal bond (Fig. 1a). Apart from a $3 \mathrm{~V}$ insertion reaction, a conversion reaction around $2 \mathrm{~V}$ can be observed and its quasi-plateau was remarkably prolonged when the working temperature was increased to $70^{\circ} \mathrm{C}$, leading to a total discharge capacity (including insertion and conversion contributions) of $660 \mathrm{mAh} / \mathrm{g}$ (Fig. 1b). This value is very close to the theoretical capacity of $712 \mathrm{mAh} / \mathrm{g}$ based on three-electron transfer. The achievement of high-voltage conversion reaction renders $\mathrm{FeF}_{3}$ a potential cathode candidate for LMBs while most conversion reactions are relevant for anodic functions. However, its conversion activity and efficiency are limited by kinetics, which is sensitive to temperature, grain size, and phase boundary conditions. The kinetic limitation lowers the practical voltage $(\sim 2 \mathrm{~V})$ where $\mathrm{FeF}_{3}$ or $\mathrm{FeF}_{2}$ is converted into $\mathrm{Fe}$ and $\mathrm{LiF}$ with respect to the thermodynamic value $(\sim 2.7 \mathrm{~V})$ reported by Li et al. ${ }^{20}$ As final
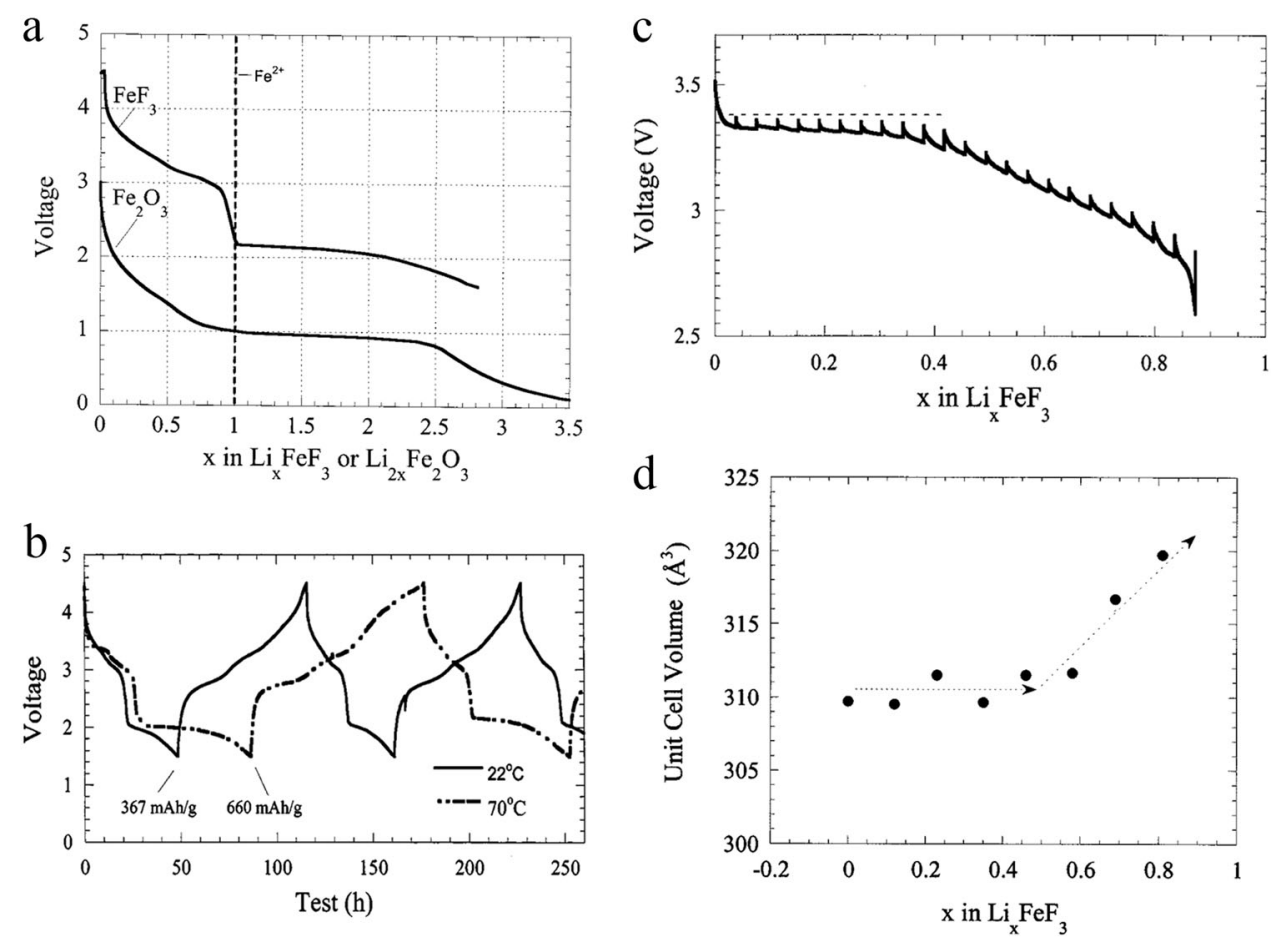

Fig. 1 a The comparison of discharge curve of $\mathrm{FeF}_{3}-\mathrm{C}$ nanocomposite as cathode with that of $\mathrm{Fe}_{2} \mathrm{O}_{3}$ as anode at the same current density of $7.58 \mathrm{~mA} / \mathrm{g}$ at $70^{\circ} \mathrm{C}$. b Discharge-charge voltage profiles of $\mathrm{FeF}_{3}-\mathrm{C}$ nanocomposite at $7.58 \mathrm{~mA} / \mathrm{g}$ depending on different running temperatures of $22^{\circ} \mathrm{C}$ and $70^{\circ} \mathrm{C}$. c Discharge curve of $\mathrm{FeF}_{3}-\mathrm{C}$ nanocomposite under a GITT mode. $\mathbf{d}$ Cell volume evolution as a function of Li insertion number in $\mathrm{FeF}_{3}$ (reproduced with permissions from refs. ${ }^{11,19}$, copyright The Electrochemical Society 2003) 
conversion products $\mathrm{Fe}$ and $\mathrm{LiF}$ nanodomains were found according to high-resolution TEM (HRTEM) and selected area electron diffraction (ED) characterizations. However, local observations cannot reliably disclose the characteristic details of the overall phase transformation, especially for the regions where serious disordering or amorphization occurs. Also, exact information about intermediate products is not extractable, especially at the transition stage from insertion to conversion.

The degree of $\mathrm{Li}$ insertion during the preceding insertion reaction has a remarkable influence on nucleation and phase separation behavior in the subsequent conversion reaction. Based on galvanostatic intermittent titration technique (GITT) and diffraction, providing information on the cell volume, $\mathrm{Li}$ insertion into $\mathrm{ReO}_{3}-\mathrm{FeF}_{3}$ was reported to firstly undergo a two-phase reaction whereby the $x$-value in $\mathrm{Li}_{x} \mathrm{FeF}_{3}$ changes roughly from $x=$ 0 to $x=0.5$. This is followed by solid-solution behavior roughly ranging from $x=0.5$ to $x=1$ (Fig. 1c, d). ${ }^{11}$ The stoichiometry was predicted by density functional theory (DFT) when investigating the Li-Fe-F phase diagram. ${ }^{21} \mathrm{~A}$ topotactic intercalation of $\mathrm{Li}$ into $\mathrm{FeF}_{3}$ was predicted only up to the thermodynamically stable $\mathrm{Li}_{1 /}$ ${ }_{4} \mathrm{FeF}_{3}$. Further $\mathrm{Li}$ injection would result in non-topotactic phase evolution and even Fe precipitation, although the topotactic lithiation is still competitive up to at least $\mathrm{Li}_{1 / 2} \mathrm{FeF}_{3}$. However, this thermodynamic reaction path appears not to be in accordance with the experimental observation. Electrochemical energy storage often involves kinetically rather than thermodynamically stable reaction products. The deepest reduction of Fe within $\mathrm{Li}_{x} \mathrm{FeF}_{3}$ is determined by the solubility limit of $\mathrm{Li}$ in $\mathrm{Li}_{x} \mathrm{FeF}_{3}$ when being in equilibrium with LiF and Fe. In view of the much higher diffusivity of $\mathrm{Li}$ than of $\mathrm{Fe}$, a kinetic reaction path with reduction of all $\mathrm{Fe}$ into $\mathrm{Fe}^{2+}$ (the lowest realistic valence state in such an ionic material) is expected along with a maximum $\mathrm{Li}$ content in $\mathrm{Li}_{x} \mathrm{FeF}_{3}$ of $x=1$ before precipitation of metallic Fe begins. The predicted voltage evolution along a reaction path with maximal reduction to $\mathrm{Fe}^{2+}$ and following nano-Fe precipitation is plotted in Fig. 2a (red dashed line). From $x=1$ to $x=3$ in $\mathrm{Li}_{x} \mathrm{FeF}_{3}$ (with the generation of $\mathrm{LiF}$ and nano-Fe), a discharge voltage of $\sim 2.15 \mathrm{~V}$ is predicted, which is very close to the experimentally conversion voltage $(\sim 2 \mathrm{~V})$. In the Li-FeF phase diagram, the reaction path with initial topotactic lithiation of $\mathrm{FeF}_{3}$ to $\mathrm{LiFeF}_{3}$ and consequent conversion to $\mathrm{Li}_{3 / 2} \mathrm{Fe}_{3 / 4} \mathrm{~F}_{3}$ and finally LiF is correspondingly tracked (red dashed line, Fig. 2b). One should note that in the kinetically stable $\mathrm{LiFeF}_{3}$ cation rearrangement minimizes face sharing between $\mathrm{Fe}$ and Li octahedra. Assuming a much lower mobility for Fe than for $\mathrm{Li}$, the kinetic path was now determined in ref. ${ }^{21}$ as the lowest energy path of the pathways characterized by the highest Fe valence. This difference in conversion and reconversion pathways naturally leads to a strong hysteresis as observed experimentally. The same kinetic pathway explains the occurrence of a rutile fluoride phase at full removal of three $\mathrm{Li}$; these calculations do not suggest $\mathrm{FeF}_{2}$ (rutile) to be formed during charging, rather a defect rutile of the composition $\mathrm{FeF}_{3}$. For larger clusters this is more reasonable than resorting to a surface charge $\left(\mathrm{FeF}_{2}\right)_{x}^{x+}$ given a removal of three $\mathrm{Li}$ in the delithiation process.

The predict nonequilibrium reconversion path includes generation of (Fe-deficient) spinel $\mathrm{Li}_{15 / 8} \mathrm{Fe}_{3 / 8} \mathrm{~F}_{3}$, ilmenite $\mathrm{Li}_{3 / 2} \mathrm{Fe}_{1 / 2} \mathrm{~F}_{3}$, and rutile $\mathrm{Li}_{3 / 4} \mathrm{Fe}_{3 / 4} \mathrm{~F}_{3}$ intermediate phases before arriving at defectrutile $\mathrm{FeF}_{3}$ as shown in Fig. $2 \mathrm{~d}$ (blue dashed line). The voltage evolution based on this nonequilibrium path is in reasonable accordance with the measured voltage profile (blue line in Fig. 2c). Although DFT predicted defect-rutile $\mathrm{FeF}_{3}$ as the ultimate recharged phase by favorably extracting $\mathrm{Li}$ from rutile-like $\mathrm{Li}_{3 /}$ ${ }_{4} \mathrm{Fe}_{3 / 4} \mathrm{~F}_{3}$, the formation of rutile $\mathrm{FeF}_{2}$ is invoked based on the experimental observation by Badway et al. ${ }^{19}$ Note that the (simulated) XRD patterns between the two phases are very similar. $^{19,21}$ An important conclusion drawn from the DFT calculation is that the voltage hysteresis is intrinsic and caused by different nonequilibrium (kinetic) reaction paths between discharge and charge according to Li-FeF phase diagram. The effect is rooted in the remarkably different mobility of Fe and $\mathrm{Li}$ cations in the fluoride host, as a consequence of which the $\mathrm{Fe}$ concentration always lags behind the equilibrium concentration for a given $\mathrm{Li}$ content (i.e., Fe excess during $\mathrm{Li}$ insertion and $\mathrm{Fe}$ deficiency during Li extraction).
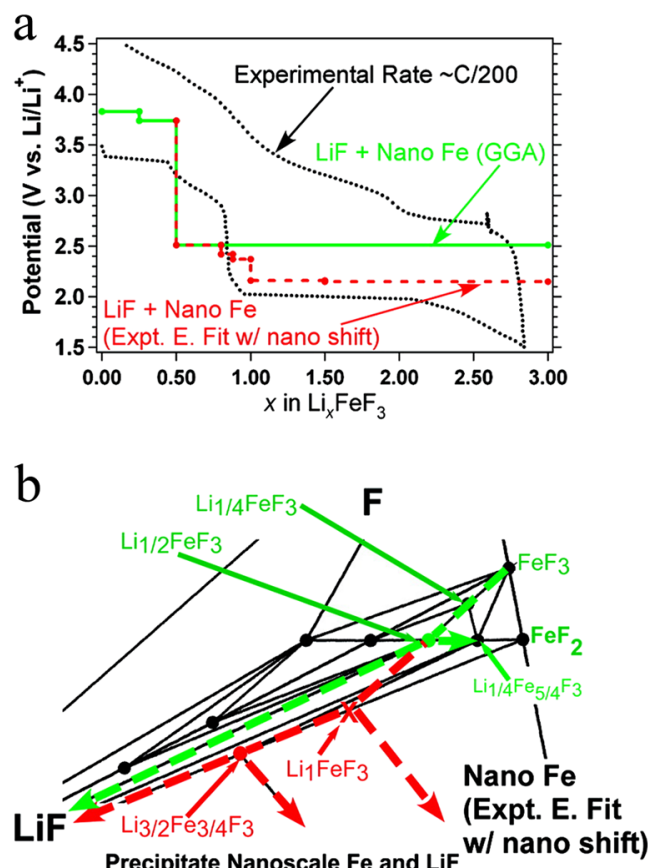

C

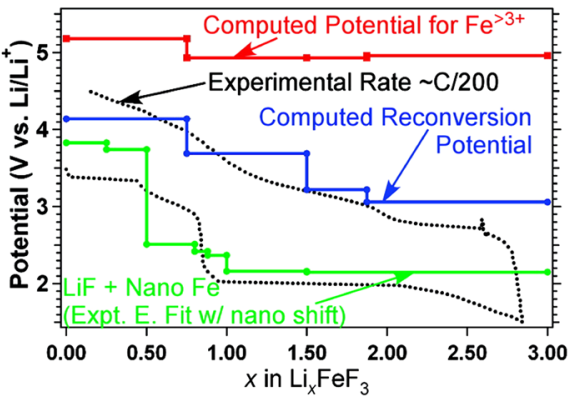

d

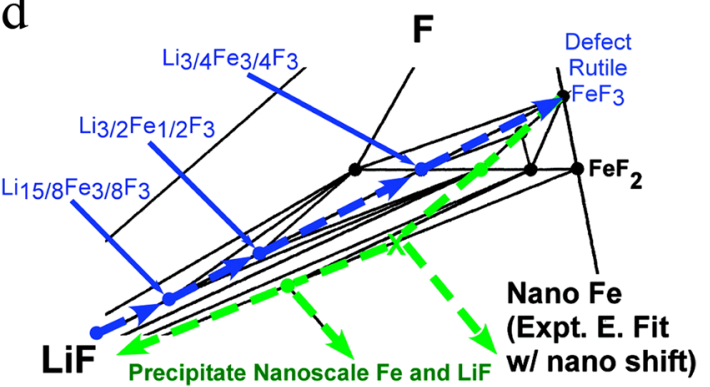

Fig. 2 a Calculated discharge voltage profile of $\mathrm{FeF}_{3}$ considering the formation of nanoscale Fe during conversion reaction (red dashed line). $\mathbf{c}$ Calculated charge voltage profile of $\mathrm{FeF}_{3}$ during reconversion reaction (blue solid line). The experimental profiles are displayed in black dotted lines. Corresponding reaction paths of $\mathrm{FeF}_{3}$ during (b) conversion (red dashed arrows) and (d) reconversion (blue dashed arrows) processes (reproduced with permission from ref. ${ }^{21}$, copyright American Chemical Society 2008) 
a



b



C

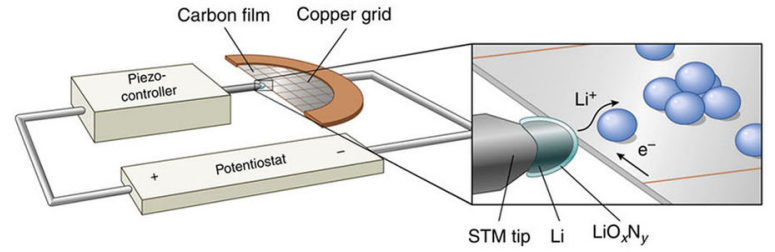

d

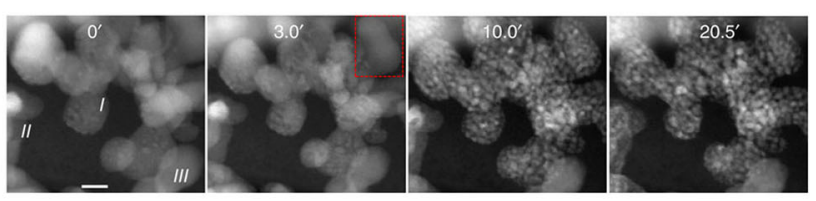

$\mathrm{e}$

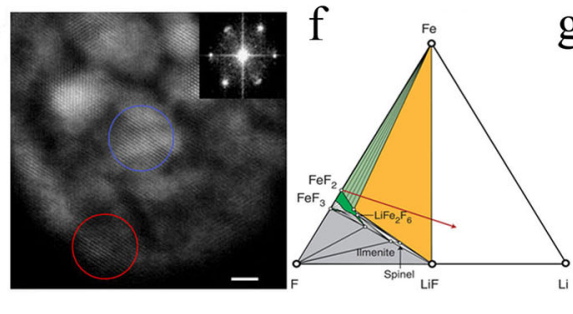

g

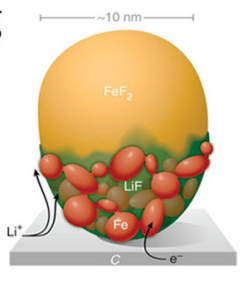

Fig. 3 a Voltage profile of $\mathrm{FeF}_{2}$ during the first discharge at $0.01 \mathrm{C}$ with different lithiation stages labeled as a-f. b Ex situ X-ray PDF profiles at corresponding electrochemical stages as shown in a (reproduced with permission from ref. ${ }^{9}$, copyright American Chemical Society 2011 ). c Scheme of electrochemical cell for in situ TEM measurements. d TEM images of a collection of particles reacting with Li as a function of reaction time. e TEM image of Fe nanoparticles converted from a single $\mathrm{FeF}_{2}$ particle, inset: fast Fourier transform (FFT) pattern of selected region. $\mathbf{f} \mathrm{Li}-\mathrm{Fe}-\mathrm{F}$ phase diagram by first-principle calculations. $\mathbf{g}$ Scheme of conversion reaction propagation within a single FeF $\mathrm{F}_{2}$ particle via a "layer-by-layer" process (reproduced from ref. ${ }^{22}$ )

With the development of advanced and especially in situ analysis technologies, more information about conversion reaction mechanism became available. In order to avoid the interference of intercalation, $\mathrm{FeF}_{2}$ with a negligible intercalation region was used as the model material by Wang et al. ${ }^{9}$ The conversion plateau during the first discharge is located at $\sim 1.7 \mathrm{~V}$ at room temperature (Fig. 3a), which is lower than the thermodynamic equilibrium value of $2.7 \mathrm{~V}^{20}$ Although the plateau voltage during the following discharge is increased to $2.3 \mathrm{~V}$, it is still lower than the thermodynamic value. The voltage hysteresis between conversion and reconversion exceeds $0.7 \mathrm{~V}$. These results indicate the relevance of kinetic pathways as inferred from DFT simulation. ${ }^{21}$ The rise of the $\mathrm{FeF}_{2}$ discharge potential after first conversion is kinetically caused and attributed to electrochemical grinding of active grains. During the conversion reaction, tiny Fe nanoparticles of $<5 \mathrm{~nm}$ were found to nucleate near the simultaneously converted LiF as a consequence of low mobility of Fe. Furthermore, these Fe nanoparticles are interconnected with each other to form a percolative electronic network superimposed to the inhomogeneously distributed insulating LiF matrix. Additional ionic transport pathways are provided by the newly generated interfaces and pores between these nanoscale phases. This scenario is concluded mainly from the combination of TEM, EELS, and PDF characterizations. HRTEM only provides the contrast for converted metallic particles, and is not effective for the contrast for lithium-containing fluorides due to weak scattering of light component elements. Therefore, the reaction mechanism cannot be clarified by TEM characterization only. EELS is sensitive to light elements and enables high-resolution ( $1 \mathrm{~nm}$ scale) compositional images of cycled electrodes. X-ray-induced PDF is sensitive to short-range order and finer microstructural details. The PDF patterns at different stages of the conversion process are shown in Fig. $3 \mathrm{~b}$ according to the corresponding synchrotron XRD patterns (Fig. 3a). From the stages $A$ to $C$ (shallow lithiation from 0 to $0.29 \mathrm{~mol} \mathrm{Li}$ ), the PDF patterns do not show any remarkable change, although the nucleation of conversion products initiates at this stage of lowest potential between B and C. The facile agglomeration of $\mathrm{FeF}_{2}$ nanoparticles leads to a longer electron transport distance which is responsible for the poor kinetics during initial lithiation (voltage dropping and then climbing). This stage is characterized by a higher voltage and is likely associated with the surface reduction of $\mathrm{Fe}^{3+}$ to $\mathrm{Fe}^{2+}$. The $\mathrm{Fe}-\mathrm{Fe}$ peaks corresponding to the formation of a-Fe become pronounced in stage $\mathrm{D}$ characterized by lithiation to $0.87 \mathrm{~mol} \mathrm{Li}$. The a-Fe signals are further intensified at the expense of those of $\mathrm{FeF}_{2}$ when the discharge process proceeds (from stages D to F). The PDF peak intensity indicates the ordering (coherence) degree or particle dimension, and its evolution here confirms a gradual particle shrinkage under electrochemical grinding. The fitting of PDF pattern at stage $F$ (fully discharged state) discloses that the average particle size of a-Fe $(\operatorname{Im} 3 \mathrm{~m})$ is around $2.6 \mathrm{~nm}$. This estimated grain size is in accordance with the atomic-scale observation of 3-5 nm Fe nanoparticles by aberration-corrected scanning TEM. These nanoparticles are interconnected by sharing a common crystallographic orientation, for example, $\{110\}$ plane. The coherence of Fe nanoparticles is likely caused by the fast diffusion of $\mathrm{F}$ out of $\mathrm{FeF}_{2}$ lattices, which promotes the nucleation and growth of Fe particles with preferred lattice alignment with the parent crystal to a certain degree.

Later, Wang et al. ${ }^{22}$ developed an in situ electrochemical cell to further investigate the Li-driven conversion reaction of $\mathrm{FeF}_{2}$ nanoparticles by in situ TEM, ED, and EELS (Fig. 3c). ${ }^{22}$ It was found that the conversion reaction starts at the surface and propagates quickly across the $\mathrm{FeF}_{2}$ nanoparticles with gradual phase segregation in the individual particles (Fig. $3 d$ ). Inside the particles, $\mathrm{FeF}_{2}$ decomposes into $\mathrm{Fe}$ crystallites of $1-3 \mathrm{~nm}$ size and amorphous Li-F, which likely retards $\mathrm{Fe}$ interdiffusion and its coarsening. According to ref. ${ }^{10}$, the disordered LiF should have a much higher ion conductivity than well-crystallized LiF. ${ }^{10}$ Similar to ex situ characterization, the interconnection of Fe crystallites with lattice alignment was also clearly observed from this in situ TEM measurement (Fig. 3e). In fact, the reaction within individual 
particles is quite fast, corresponding to a discharge rate of 5-20C. This real-time observation challenges the traditional viewpoint that solid-solid conversion kinetics is intrinsically sluggish. It is believed that high rate in practical batteries may be feasible provided a suitable electrode architecture is achieved with most fluoride nanoparticles homogeneously linking to current collector or at least a conductive network. By first-principle calculations based on DFT, Wang et al. ${ }^{9,22}$ predicted an equilibrium path with the formation of a tri-rutile $\mathrm{LiFe}_{2} \mathrm{~F}_{6}$ intermediate, which is then converted to $\mathrm{Fe}$ and $\mathrm{LiF}$ (Fig. 3f). Unexpectedly, the $\mathrm{Fe}^{3+}$ component in $\mathrm{LiFe}_{2} \mathrm{~F}_{6}$ cannot be detected by in situ EELS and also the lattice parameter change by in situ $E D$, indicating that the actual reaction follows a nonequilibrium path (cf. ref. ${ }^{21}$ ). The in situ measurement disclosed that Li ions move rapidly at the surface, but much more slowly when having been incorporated into bulk $\mathrm{FeF}_{2}$. The coupling of ion and electron transports across nanoscale bulk and multiphase interfaces complicates the reaction path, which overall follows a "layer-by-layer" propagation process (Fig. 3g).

Ma and Garofalini ${ }^{23,24}$ used a dynamically adaptive force field approach to get deeper insight into the molecular mechanism of the $\mathrm{FeF}_{2}$ conversion reaction. Two potential diffusion channels along [001] and [110] directions with different energy were investigated. The barrier along the [001] channel is only $0.05 \mathrm{eV}$, whereas that along [110] is as high as $\sim 1 \mathrm{eV}$. The former enables "high-rate" Li transport even with a small fraction of intercalation, followed by the formation of amorphous Li-F and Fe clusters. Clustering of Fe leaves under-bonded $\mathrm{F}$ ions, which combine with adjacent $\mathrm{Li}$ to form a $\mathrm{Li}-\mathrm{F}$ network. This network is highly $\mathrm{Li}$ deficient and allows extra $\mathrm{Li}$ ions to pass and enter into the next subsurface layer. More $\mathrm{Li}$ uptake triggers the transformation of amorphous Li-F to crystalline LiF. At any rate, the insulating nature of crystalline LiF is detrimental for the electronic and ionic transport in the electrode.

Investigating thin-film architectures that are free of conductive additive and binder is beneficial for scrutinizing intrinsic electrochemical parameters. ${ }^{25} \mathrm{FeF}_{2}$ thin films are easier to fabricate than $\mathrm{FeF}_{3}$ films using physical vapor deposition. ${ }^{26}$ The conversion reaction can even be investigated by lithiation of the $\mathrm{FeF}_{2}$ thin film. If very thin films are used, the kinetic influence is lowered and the conversion reaction should be rather thermodynamically controlled. Rangan et al. ${ }^{27}$ observed that ultrathin $(\sim 5 \mathrm{~nm}) \mathrm{FeF}_{2}$ films facilely convert to interconnected metallic Fe nanodomains of $\sim 3 \mathrm{~nm}$ surrounded by LiF under deposition of atomic Li. LiF was found to be better crystallized than under electrochemical lithiation. The inhomogeneous distribution of $\mathrm{Li}$ and Fe components was clearly observed by EELS mapping. During this chemical lithiation, no $\mathrm{Fe}^{+}$signal was detected by X-ray and ultraviolet photoemission spectroscopy (XPS and UPS) performed in an ultrahigh vacuum environment. Thorpe et al. ${ }^{28}$ grew an epitaxial $\mathrm{FeF}_{2}$ (110) film on a $\mathrm{MgF}_{2}$ (110) single crystal substrate for atomic lithium exposure. They discovered that the lithiation of $\mathrm{FeF}_{2}$ initiates in a layer-by-layer manner (with a depth of $\sim 1.2 \mathrm{~nm}$ ) because of a high $(\sim 1 \mathrm{eV})$ kinetic barrier for the (110) channel as predicted by Garofalini et al. ${ }^{23,24}$ Then the reaction progresses in a non-planar manner, since the newly generated interfaces between nano-Fe and LiF provide additional paths for Li penetration and therein preferential nucleation occurs. As intermediate product of atomic lithiation $\mathrm{Fe}_{x} \mathrm{Li}_{2-2 x} \mathrm{~F}_{2}$ was detected by angle-resolved XPS and the Fe solubility was ascribed to substitution in the LiF lattice. Ko et al. ${ }^{29}$ chemically lithiated $\mathrm{FeF}_{2}$ thin films by $n$-butyl-lithium in order to generate an optimized metal network. They estimated the electron conductivity of the lithiated film electrode based on the architecture of interdigitated electrodes by electrochemical impedance spectroscopy and direct current polarization. The high value of $1-8 \mathrm{~S} / \mathrm{cm}$ indicates the formation of an electronically percolating Fe network. This percolating path is somewhat epitaxial with less grain boundaries and therefore helpful to further improve the electron conductivity.

Most recently, a different picture of the $\mathrm{FeF}_{3}$ conversion reaction was given based on hard X-ray spectro-imaging, in situ synchrotron XAS, hybrid functional DFT calculations, and GITT. ${ }^{16,30}$ Hard X-ray spectro-imaging enables the visualization of electrochemically driven phase transformation even on a nanoscale (Fig. $4 a, b)$. It was observed that the phase transformation is quite homogeneous for both conversion and reconversion reactions, unlike the inhomogeneous intercalation behavior in $\mathrm{LiFePO}_{4}$. This imaging suggests that the final charge product is characterized by an Fe oxidation state of +2 . This statement disagrees with firstprinciple calculation claiming appearance of $\mathrm{Fe}^{3+}$-containing products after recharging the LiF:Fe nanocomposite. The authors propose that the phase transformation paths are symmetrical during discharge and charge processes (in contrast to the previous statement that the reaction paths are asymmetric with the generation of different intermediate products, leading to intrinsic voltage hysteresis), ${ }^{21}$ and that the voltage hysteresis mainly stems from the ohmic voltage drop, reaction overpotential, and different spatial distributions of electroactive (intermediate) products (i.e., compositional inhomogeneity). Their suggested reversible reaction path is: rhombohedral $\mathrm{FeF}_{3} \rightarrow$ tri-rutile $\mathrm{Li}_{0.25} \mathrm{FeF}_{3} \rightarrow$ tri-rutile $\mathrm{Li}_{0.5} \mathrm{FeF}_{3} \leftrightarrow$ rutile $\mathrm{FeF}_{2}+\mathrm{LiF} \leftrightarrow \mathrm{Fe}+3 \mathrm{LiF}$ (Fig. 4d). This leaves much room for mitigating the voltage hysteresis and improving the energy efficiency. They noted another interesting phenomenon. They found a remarkable amount of metallic Fe when $x=0.6$ in $\mathrm{Li}_{x} \mathrm{FeF}_{3}$ corresponding to an intermediate oxidation state of Fe (Fig. 4c). It indicates that the reduction of $\mathrm{Fe}^{2+}$ to metallic $\mathrm{Fe}$ may begin at outer surfaces (where $\mathrm{Fe}^{3+}$ has been reduced to $\mathrm{Fe}^{2+}$ ) before the intercalationtype reduction of $\mathrm{Fe}^{3+}$ to $\mathrm{Fe}^{2+}$ is completed. The lithiation of $\mathrm{FeF}_{3}$ is thought to proceed from the surface to the core of an individual active particle. Due to kinetic limitation, the reaction in an electroactive particle likely does not progress when the subsequent reaction in another particle starts under galvanostatic condition. Based on the core-shell reaction model, unreacted FeF $_{x}$ is mainly located at the core and LiF and Fe nanodomains form at the shell during discharging, whereas during recharging the situation is opposite. This leads to compositional inhomogeneity and an asymmetric voltage profile. A distinct overpotential is required to initiate nucleation and growth of new phases, and to drive the mass and interface transport. Liu et al. ${ }^{31}$ observed a hysteresis of $280 \mathrm{mV}$ (vs. >1 V as usually observed even at low rate) by GITT with a long relaxation time of $72 \mathrm{~h}$. They thought that this hysteresis is caused by the energy barrier for nucleation of LiF and Fe nanodomains (followed by coalescence of Fe nanoparticles and a reduced $\mathrm{Fe} / \mathrm{LiF}$ interfacial area), rather than by intrinsically different reaction paths. Zhang et al. ${ }^{32}$ obtained information on coordination numbers and bond lengths of Fe-F and Fe-Fe bonds during insertion and conversion reactions of $\mathrm{FeF}_{3}$ by fitting in situ $X A S$, and deduced sequential reaction pathways consisting of twophase intercalation (from $x=0$ to 0.46 ), single-phase intercalation (from $x=0.46$ to 0.92 ), and conversion reaction (from $x=0.92$ to 2.78) steps for $\mathrm{Li}_{x} \mathrm{FeF}_{3}$. These examples from literatures clearly show the complexity of the process and that no final conclusion on the mechanism has been achieved so far.

Room temperature Na-based batteries are receiving more and more attention in view of their resource abundance and lost cost. Although the larger size of the $\mathrm{Na}$ ion lowers the polarizing force and potentially enables higher rate performance during intercalation, the transport of $\mathrm{Na}$ ions across multiphase interfaces is expected to be sluggish due to its large volume. It has been reported that the Na-driven conversion capacity is typically inferior to the corresponding Li-driven one under comparable conditions. $^{33}$ Na-based conversion reactions usually lead to insufficient conversion depth and less conductive wiring network owing to mass transport limitation. For these reasons, dense $\mathrm{FeF}_{x}$ 
a

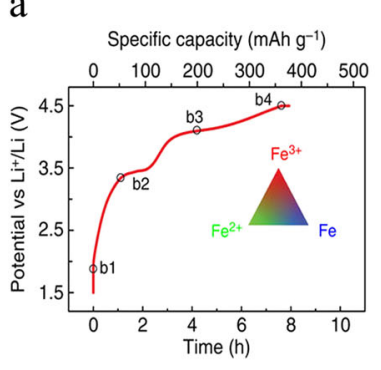

b

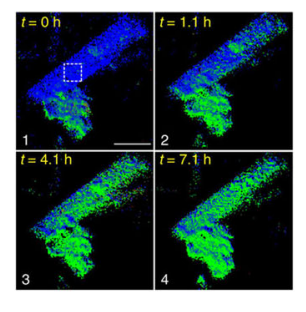

C

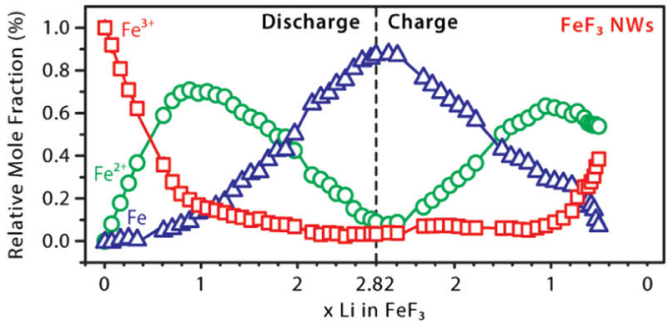

d
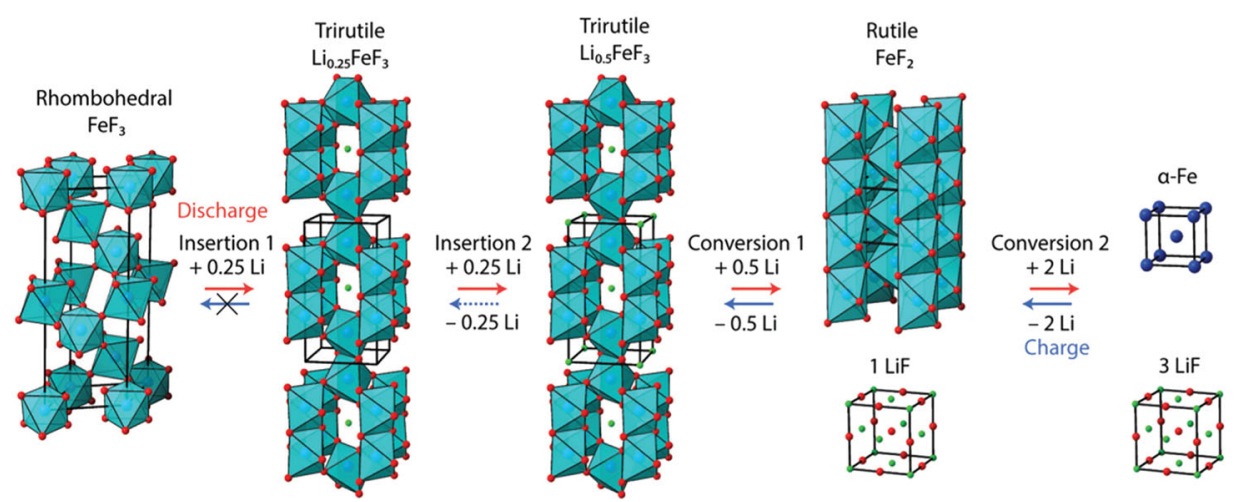

Fig. 4 a Voltage profile of $\mathrm{FeF}_{3}$ during recharging process to $4.5 \mathrm{~V}$ in an operando cell with four stages (small black circles) for data collection by hard X-ray spectro-imaging. b Mapping images of Fe element with different valence states at corresponding electrochemical stages as shown in a (reproduced from ref. $\left.{ }^{16}\right)$. c Fe valence state and phase evolution of $\mathrm{FeF}_{3}$ nanowires during cycling, estimated by linear combinational fitting analysis of in situ XAS spectra. d Reaction pathways and structure evolution of FeF ${ }_{3}$ during conversion reaction concluded from both experimental and calculation results (reproduced with permission from ref. ${ }^{30}$, copyright American Chemical Society 2016)

was rarely reported as conversion cathode for $\mathrm{Na}$ batteries. He et al. $^{34}$ showed that the reversible Na-storage capacity for $\mathrm{FeF}_{2}$ nanoparticles is merely $100 \mathrm{mAh} / \mathrm{g}$ even when the cut-off discharge voltage is extended to $1 \mathrm{~V}$. The poor performance is rooted in the heterogeneous sodiation mechanism, characterized by regular conversion at the surface $\left(\mathrm{FeF}_{2}+2 \mathrm{Na}^{+}+2 \mathrm{e}^{-} \rightarrow 2 \mathrm{NaF}\right.$ $+\mathrm{Fe})$ and disproportionation reaction in the core $\left(\mathrm{FeF}_{2}+\mathrm{Na}^{+}+\right.$ $\left.\mathrm{e}^{-} \rightarrow 1 / 3 \mathrm{Na}_{3} \mathrm{FeF}_{6}+2 / 3 \mathrm{Fe}\right)$. The $\mathrm{Fe}$ nanocrystallites in sodiated particles are $1-4 \mathrm{~nm}$ in size and are embedded in the $\mathrm{Na}_{3} \mathrm{FeF}_{6}$ matrix, which is coated by a NaF layer stemming from the surface conversion reaction. Fe nanocrystallites are also interconnected to form an electron-conductive network as in the case of the Fe/LiF system. The NaF coating can passivate the particle surface and retard inward diffusion of $\mathrm{Na}$, leading to insufficient $\mathrm{Na}$ supply, which promotes the disproportionation reaction.

\section{PHASE TRANSFORMATION IN IRON OXYFLUORIDES}

Pure $\mathrm{FeF}_{2}$ and $\mathrm{FeF}_{3}$ are electronically and ionically insulating. Doping appears to be a good strategy to improve their intrinsic conductivities. Pereira et al. ${ }^{12}$ firstly reported a series of nanostructured O-doped fluorides (i.e., iron oxyfluoride) with different oxygen contents as conversion cathodes for $\mathrm{Li}$ batteries. ${ }^{12}$ They were prepared by a solution method with $\mathrm{Fe}$ metal and $\mathrm{H}_{2} \mathrm{SiF}_{6}$ solution as precursors, followed by heating treatment under different atmosphere, temperature, and time, and then by ball milling with activated carbon to achieve a composition in the range from $\mathrm{FeF}_{2}$ to FeOF. Among these oxyfluorides, FeOF is more stable than other $\mathrm{FeO}_{x} \mathrm{~F}_{2-x}$ compositions and has a theoretical capacity of $885 \mathrm{mAh} / \mathrm{g}$ based on a three-electron conversion reaction into $\mathrm{Fe}+\mathrm{LiF}+\mathrm{Li}_{2} \mathrm{O}$, which is distinctly higher than for $\mathrm{FeF}_{3}(712 \mathrm{mAh} / \mathrm{g})$ and for $\mathrm{FeF}_{2}(571 \mathrm{mAh} /$ g). FeOF also exhibits a higher reaction voltage, better cycling performance, and higher energy efficiency than $\mathrm{FeF}_{2}$. FeOF exhibits the rutile structure of $\mathrm{FeF}_{2}$ but the high oxidation state of $\mathrm{Fe}^{3+}$ as in $\mathrm{FeF}_{3}$. As a charge-transfer semiconductor its electronic conductivity is higher than for the Mott-Hubbard insulator $\mathrm{FeF}_{2}{ }^{35}$ The decrease of the $c$-lattice parameter is an indicator for the oxygen content and the oxidation degree. Since $\mathrm{O}^{2-}$ and $\mathrm{F}^{-}$have similar sizes, the substitution of $\mathrm{O}^{2-}$ may occur randomly throughout the anion sublattice, without long-range ordering of $\mathrm{O}$ and $\mathrm{F}$ (some short-range ordering is still maintained).

The loss of long-range ordering and the possibility of a varying mixed anionic environment in FeOF severely aggravate the structure analysis especially during the conversion reaction. Wiaderek et al. ${ }^{36}$ used PDF and NMR, the typical tools for local microstructure characterization, to separately probe the local environments of $\mathrm{Li}, \mathrm{O}$, and $\mathrm{F}$ and to gain insight into the atomic structure, phase, and even particle evolution. It was found that during cycling of FeOF anionic partitioning occurs, with the formation of an amorphous F-rich rutile phase and a nanocrystalline O-rich rock salt phase. The charged electrode no longer consists of a single oxyfluoride phase. The reaction of F-rich and O-rich phases progresses sequentially with an unexpected preferential reaction with the former during both discharge and recharge. The discharge curve consists of a sloped high-voltage region (solid-solution-like intercalation from $\sim 3$ to $\sim 2 \mathrm{~V}$ terminated at $x=\sim 0.5$ for $\mathrm{Li}_{x} \mathrm{FeOF}$ ) and a plateau region (two-phase-like conversion mainly around $2 \mathrm{~V}$ terminated at $x=\sim 1.9$ ) at $50^{\circ} \mathrm{C}$. PDF disclosed a highly reversible phase transition during cycling. The intensity of PDF peaks is associated with the relative abundance of the corresponding atom-atom distances (i.e., coordination number or phase abundance), and their positions are related with the bond length. The first PDF peak at $\sim 2.0 \AA$ corresponds to both Fe$\mathrm{O}$ (for rock salt) and Fe-F (for rutile) bonds. The short distance of $2.5 \AA$ corresponds to the nearest-neighbor Fe-Fe bonds in Fe nanoparticles $(2.5-3.0 \mathrm{~nm})$ as discharge products based as 
a

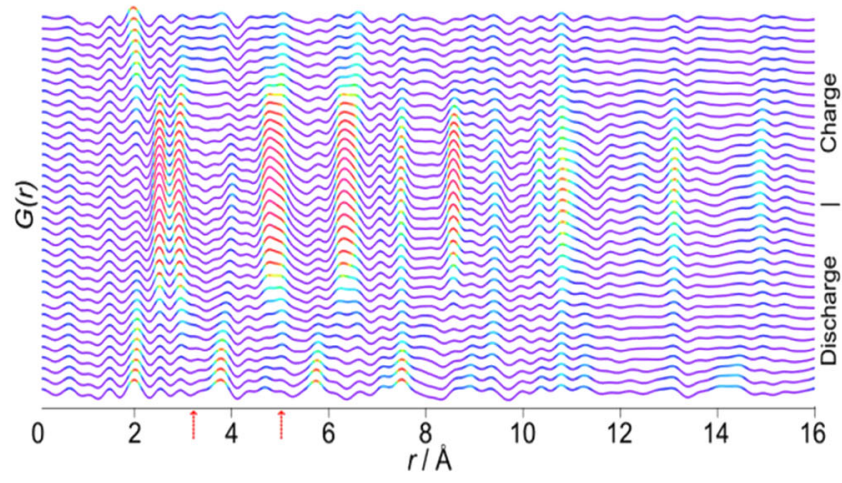

b

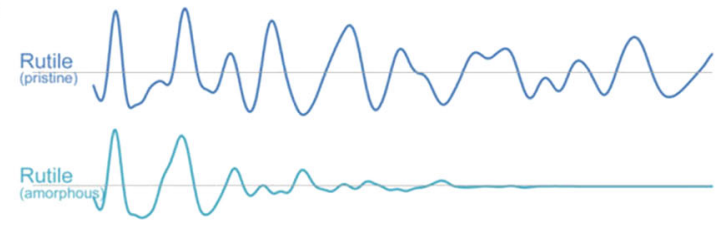

sิ



$\mathrm{C}$

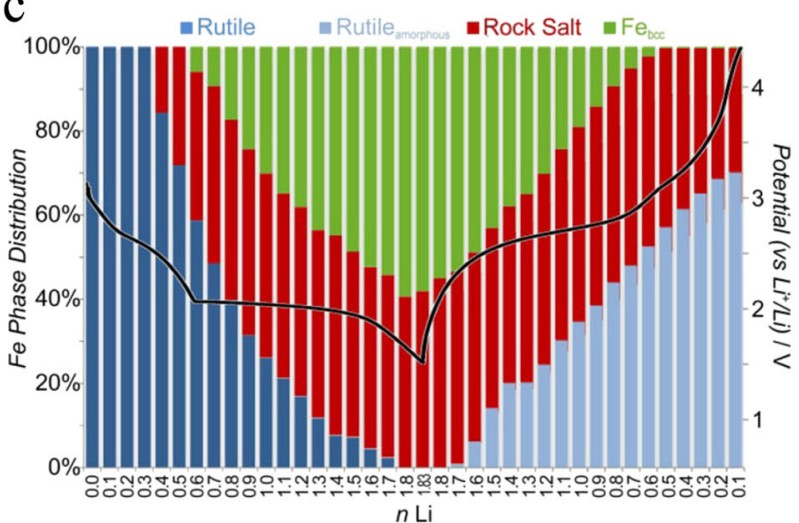

$n \mathrm{Li}$

d

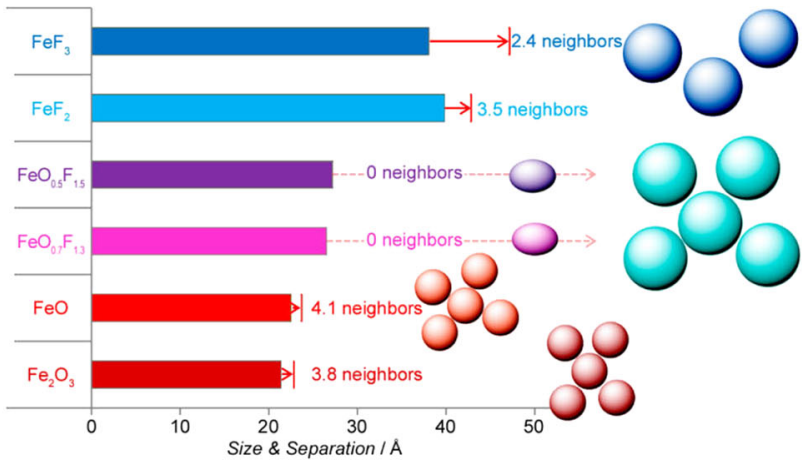

Fig. 5 a In situ X-ray PDF profiles of oxyfluoride during the first cycling. Distances characteristic of rock salt intermediate is indicated by arrows. Relative peak intensity is reflected from the color change. b Simulated PDFs corresponding to pristine and amorphous rutile phases, rock salt phase, and Fe nanoparticles. c Fe contained phase ratio and evolution during conversion reaction, estimated from PDF profile fitting. d Scheme of converted Fe nanostructure comparison among Fe oxyfluorides, fluorides, and oxides. The dominant Fe particle size (bars), average particle-particle separation (arrows), and number of well-defined neighboring particles are indicated (reproduced with permission from ref. ${ }^{36,38}$, copyright American Chemical Society 2013 and 2014, respectively)

simulations show (Fig. 5a, b). The peak at $5.0 \AA$ corresponds to the formation of an intermediate rock salt product and was not observed in the pristine or discharged electrodes, but it still exists in the recharged state. The PDF curve features of the charged products are similar to those of the pristine electrode when the $x$ axis value $(r)$ is smaller than $\sim 5 \AA$. However, the features are weakened at higher $r$-value, indicating degradation of crystallinity or decrease of particle size after cycling. For a similar reason, the pristine rutile phase can be expected to become disordered during discharge and the reformed rutile phase to be amorphous during recharging. The rock salt intermediate has a similar microstructure and lattice distortion as $\mathrm{a}-\mathrm{LiFeO}_{2}$ and becomes significant at $x=\sim 0.4$ before the conversion plateau begins (Fig. 5c). Residuals of this rock salt phase are still present even after termination of the charging when all the Fe nanoparticles have been converted into amorphous rutile. The residual amount of the rock salt phase is proportional to the $\mathrm{O}$ content in the oxyfluoride. Similar to the case of $\mathrm{FeF}_{3}$, it is confirmed that the formation of $\mathrm{Fe}$ nanoparticles occurs also prior to the conversion plateau. The fact that the charged phases are a mixture of O-rich and F-rich phases indicates that providing a single phase with mixed anions is unnecessary as long as an extremely intimate physical mixture of oxide and fluoride can be achieved. An irreversible O/F reaction sequence should be responsible for the observed voltage hysteresis during cycling. A reverse-step potentiostatic intermittent titration technique (PITT) was used to estimate the true hysteresis by eliminating the nucleation-induced overpotential. ${ }^{37}$ Under high-resolution PITT conditions with $10 \mathrm{mV}$ steps involving extremely small current densities $(C / 1000)$, the hysteresis of conversion region for oxyfluoride is estimated as $0.7 \mathrm{~V}$, remarkably smaller than the $1.3 \mathrm{~V}$ for $\mathrm{FeF}_{2}$ and $\mathrm{FeF}_{3}$.

Wiaderek et al. ${ }^{38}$ further compared the oxyfluoride with a series of Fe-based fluorides and oxides to explore the influence of anion chemistry of pristine electrodes on the defect density in $\mathrm{Fe}$ lattices, particle size, shape, and interparticle interaction. The defect concentration in Fe lattices can be estimated by the intensity change of the Fe-Fe PDF peaks and the deviation of the second nearest-neighbor Fe-Fe distance. Compared with the single anion system, the mixed-anion system leads to a different nanostructure distribution scenario. The Fe nanostructures after lithiating oxyfluoride have no well-defined neighbors (at $60^{\circ} \mathrm{C}$ ), whereas they have two to four neighbors for $\mathrm{FeF}_{x}$ or $\mathrm{FeO}_{x}$ (Fig. $5 \mathrm{~d}$ ). In other words, for $\mathrm{FeO}_{x} \mathrm{~F}_{y}$ the converted Fe nanoparticles usually do not interconnect to form conductive networks or chains as in the case of $\mathrm{FeF}_{x}$. The particle size of $\mathrm{Fe}$ increases with the increase of the $\mathrm{F}$ content, and the local defect concentration increases with higher $\mathrm{O}$ content. According to ref. ${ }^{38}$, the strong affinity of $\mathrm{O}$ to $\mathrm{Fe}$ is likely to limit Fe mobility and defect healing. Accordingly, the conversion reaction of the O-rich phase results in a smaller size of discrete nanoparticles, whereas an improved mobility of Fe atoms for F-rich phase leads to larger particle size or favorable particle growth.

Fe-based oxyfluoride can also exist in an inhomogeneous form (e.g., core-shell structure) with a different $\mathrm{O} / \mathrm{F}$ concentration distribution within a single particle, either by thermal oxidation of the fluoride $\left(\mathrm{FeF}_{3}\right)$ or by surface fluorination of the oxide $\left(\mathrm{Fe}_{2} \mathrm{O}_{3}\right.$, $\left.\mathrm{Fe}_{3} \mathrm{O}_{4}\right) .^{39-41}$ Both the inhomogeneous doping and the surface treatment improved the electrochemical performance, for 
example, uplifting reaction voltage and promoting capacity retention. According to Zhou et al. ${ }^{40}$ the metastable FeOF is difficult to be tailored by thermal fluorination of Fe oxide; rather, $\mathrm{FeOF}$ is prone to decompose into interconnected $\mathrm{FeF}_{3}$ and $\mathrm{Fe}_{2} \mathrm{O}_{3}$ nanodomains resulting in a porous morphology. Kim et $\mathrm{al}^{42}$ investigated the phase evolution of $\mathrm{FeO}_{0.7} \mathrm{~F}_{1.3}$ nanoparticles with an F-rich core covered by a thin O-rich shell during conversion reaction. They reported that the O-rich rutile shell converts to rock salt $\mathrm{Li}-\mathrm{Fe}-\mathrm{O}(-\mathrm{F})$ and metallic Fe during lithiation. Both products show high lattice coherency, which is not diadvantageous for charge transport. The generated O-rich rock salt phase stays stable during the following cycling and its surface accumulation enables the particle integrity. The particle morphology is stable and characterized by the initial core-shell structure, indicating limited interdiffusion of $\mathrm{F}$ and $\mathrm{O}$ during conversion. The dominant redox reaction occurs at the F-rich core, where the Fe $(2-3 \mathrm{~nm})$ and LiF nanodomains are reversibly generated. In such core-shell structures, percolating conductive networks consist of rock salt Li-Fe-O $(-F)$ and metallic Fe with high lattice alignment. This phase evolution scenario roughly conforms with that of ball-milled $\mathrm{FeO}_{x} \mathrm{~F}_{2-x} / \mathrm{C}$ nanocomposites with homogeneous $\mathrm{O} / \mathrm{F}$ distributions as reported by Cosandey and colleagues. ${ }^{43}$ These authors also observed the formation of a Li-Fe-O-F-like rock salt phase during the conversion process together with $\mathrm{Fe}$ and LiF nanodomains. This rock salt phase is also electrochemically irreversible and coexists with an amorphous rutile phase during reconversion. The authors assume that the capacity degradation is caused by the gradually decreased amount of amorphous rutile phase and the corresponding increase of less active rock salt phase during further cycling. ${ }^{44}$

As far as $\mathrm{Na}$ storage is concerned, the more conductive oxyfluoride displayed a much better storability than pure $\mathrm{FeF}_{x \text {, }}$ especially when resorting to tailored nanostructures, as they are often obtained by wet-chemical methods. ${ }^{45}$ Zhou et al. ${ }^{46}$ investigated the Na-storage phase transformation behavior in ballmilled $\mathrm{FeO}_{0.7} \mathrm{~F}_{1.3} / \mathrm{C}$ nanocomposites with active particle sizes as small as $12 \mathrm{~nm}$. The first discharge process showed a sloped curve from 2.4 to $\sim 1.5 \mathrm{~V}$ and then a plateau around $1.5 \mathrm{~V}$ at $50^{\circ} \mathrm{C}$. The released capacity is found to be as high as $496 \mathrm{mAh} / \mathrm{g}$, corresponding to $1.7 \mathrm{Na}$ per $\mathrm{FeO}_{0.7} \mathrm{~F}_{1.3}$, which is still lower than the theoretical capacity of $787.7 \mathrm{mAh} / \mathrm{g}$ based on three-electron transfer. The second discharge process releases a capacity of $414 \mathrm{mAh} / \mathrm{g}$ with a different electrochemical curve profile, indicating the development of a conversion mechanism. During the initial intercalation from 2.4 to $1.5 \mathrm{~V}$, the rutile structure of $\mathrm{FeO}_{0.7} \mathrm{~F}_{1.3}$ is preserved after $0.7 \mathrm{Na}$ insertion (corresponding to $210 \mathrm{mAh} / \mathrm{g}$ ). After the following conversion from 1.5 to $1 \mathrm{~V}$, rutile $\mathrm{Na}_{0.7} \mathrm{FeO}_{0.7} \mathrm{~F}_{1.3}$ is decomposed into fine $\mathrm{Fe}$ nanoparticles $(2 \mathrm{~nm})$ and $\mathrm{NaF}$ matrix coexisting with the newly formed rock salt $\mathrm{Na}_{1.4} \mathrm{FeO}_{1.4} \mathrm{~F}_{0.6}$. During the reconversion to $2.3 \mathrm{~V}$, Fe reacts favorably with $\mathrm{NaF}$ to form an amorphous rutile $\mathrm{Na}_{0.6} \mathrm{FeF}_{2.6}$ still with the rest of unconverted rock salt phase. During further recharging up to $3.5 \mathrm{~V}, \mathrm{Na}$ ions are further extracted from both the intermediate rutile and rock salt phases. The authors assume that the Na-driven conversion paths for $\mathrm{FeO}_{0.7} \mathrm{~F}_{1.3}$ are roughly similar to $\mathrm{Li}$-driven ones. This statement is different from previous reports on other conversion systems (e.g., pure fluorides, oxides, and nitrides), where cation size can significantly impact reaction path and conductive network evolution. ${ }^{33,34}$

Variations of the storage properties can also be achieved by introducing hydration water into fluoride lattices, however likely, leading to the structural evolution to open-framework phases, for example, hexagonal tungsten bronze (HTB) or pyrochlore. ${ }^{13,14}$ In such an open-framework phase, inserted $\mathrm{H}_{2} \mathrm{O}$ molecules would be seriously distorted or delocalized owing to the strong hydrogen bonding with ligands. The conversion mechanism (path) and spatial distribution of (intermediate) products are thought to be associated with the original phase structure. Based on first- principle calculations, Li et al. ${ }^{47}$ reported that the water molecules are isolated in the HTB tunnels and form strong hydrogen bonding with $\mathrm{F}$ ions, enabling the mitigation of structure distortion in $\mathrm{HTB}$ framework $\left(\mathrm{FeF}_{3} \cdot 0.33 \mathrm{H}_{2} \mathrm{O}\right) . \mathrm{Li}^{+}$insertion into the water-accommodating tunnel can change the torsion angles of $\mathrm{FeF}_{6}{ }^{3-}$ octahedral chains, responsible for a wide reaction voltage window. $\mathrm{Li}_{0.66} \mathrm{FeF}_{3} \cdot 0.33 \mathrm{H}_{2} \mathrm{O}$ is most stable with a maximum amount of $\mathrm{Li}$. More $\mathrm{Li}$ insertion leads to a cleavage of the Fe- $\mathrm{F}$ bond and to the conversion reaction $\mathrm{Li}_{3} \mathrm{FeF}_{6} \rightarrow \mathrm{LiFeF}_{4}+$ $2 \mathrm{LiF}$ (i.e., decomposing a chain of octahedral structure $\left(\mathrm{FeF}_{6}{ }^{3-}\right.$ ) into tetrahedral structure $\left(\mathrm{FeF}_{4}{ }^{-}\right)$and $\left.\mathrm{LiF}\right)$. PDF analysis was also applied to disclose the conversion mechanism of HTB framework by Dambournet et al. ${ }^{48}$ According to this work, disordered rutile and rock salt phases and finally Fe/LiF nanodomains are generated along with the collapse of HTB framework with anionic vacancies $\left(\mathrm{FeF}_{2.2}(\mathrm{OH})_{0.8-x} \mathrm{O}_{x / 2} \square_{x / 2}\right)$ during conversion reaction. The existence of anionic vacancies is observed to be beneficial for the enhancement of the reversible capacity, and however the exact reason for this still remains unclear. Similar to the case of FeOF, the disordered rutile phase rather than the pristine one is the dominating charged product. Later, Pohl et al. ${ }^{49}$ and Conte et al. $^{50}$ found by combining multiple advanced characterization tools, for example, in situ XAS and Mossbauer spectroscopy, that also amorphous $\mathrm{FeF}_{3}$ or a bronze phase may form after cycling the hydrated HTB framework. Although the exact phase evolution mechanism for open-framework systems is still under debate, the voltage profile for a conversion-type open framework is indeed different from that of dense FeOF or $\mathrm{FeF}_{3}$. Most recently, $\mathrm{Li}$ and colleagues $^{17}$ and $\mathrm{Li}$ et al. ${ }^{51}$ discovered that under long-term cycling of such a conversion reaction, the intercalation-like region at higher voltage $(2.5-3 \mathrm{~V})$ is still well maintained and the capacity loss gradually occurs in the conversion region (1.5-2 V), regardless of whether well-crystallized HTB or disordered pyrochlore phases are involved. In other words, the degradation of the low-voltage conversion region does not compromise the intercalation-like region at higher voltage, which is always highly reversible. However, for a densely structured fluoride, the capacity degradation occurs simultaneously in both electrochemical stages, resulting in a more serious de-activation. Na-storage is expected to be further activated by an open-framework strategy, especially for the pyrochlore phase $\left(\mathrm{FeF}_{3} \cdot 0.5 \mathrm{H}_{2} \mathrm{O}\right)$ with interconnected $3 \mathrm{D}$ open channels. ${ }^{14} \mathrm{Li}$ et al. ${ }^{14}$ firstly reported that the reversible capacity of $\mathrm{FeF}_{3} \cdot 0.5 \mathrm{H}_{2} \mathrm{O}$ can be as high as $250 \mathrm{mAh} / \mathrm{g}$, exceeding the theoretical intercalation capacity based on one-electron transfer. It indicates involvement of a $\mathrm{Na}$-driven conversion reaction. By near-edge X-ray absorption fine structure spectra (NEXAFS), Ali et al. ${ }^{52,53}$ confirmed the reversible formation and splitting of $\mathrm{NaF}$ during (de)sodiation, which is responsible for the good reversibility of $\mathrm{Na}$-based conversion in pyrochlore fluoride.

\section{CONVERSION SYSTEMS WITH OTHER REDOX ELEMENTS}

In contrast to transition metal oxides, in transition metal fluorides non-Fe redox centers such as $\mathrm{Mn}, \mathrm{Co}$, and $\mathrm{Ni}$ have not shown to be electrochemically active at expected thermodynamic potentials. However, two kinds of conversion fluorides based on $\mathrm{Bi}$ or $\mathrm{Cu}$ redox chemistry $\left(\mathrm{BiF}_{3}, \mathrm{BiOF}\right.$, and $\left.\mathrm{CuF}_{2}\right)$ are worthy of concern. ${ }^{54-56}$ The related conversion reactions occur in the cathodic voltage range and do not undergo formation of intermediate intercalation products as in the case of $\mathrm{FeF}_{3}$. $\mathrm{CuF}_{2}$ has a theoretical capacity of $528 \mathrm{mAh} / \mathrm{g}$ based on two-electron conversion to $\mathrm{Cu}$ and LiF with a high thermodynamic potential of $3.55 \mathrm{~V} .^{56}$ It therefore results in an exceptionally high energy density of $1874 \mathrm{Wh} / \mathrm{kg}$ ( $300 \%$ higher than that of $\mathrm{LiCoO}_{2}$ intercalation cathode). Its volumetric energy density is also very high, viz. $7870 \mathrm{Wh} / \mathrm{L}$, exceeding even the value for $\mathrm{CF}_{x}(\sim 6000 \mathrm{Wh} / \mathrm{L})$. The usual preparation route is via energy ball milling which results in $\mathrm{CuF}_{2}-\mathrm{C}$ or $\mathrm{CuF}_{2}$-oxide nanodomains. Tools such as admixing carbon or oxide have not succeeded in 
preventing the dissolution of $\mathrm{Cu}^{+}$species, which is a problem especially during recharging. ${ }^{57}$ This dissolution process causes a loss of electroactive species and so far restricts the use of $\mathrm{CuF}_{2}$ as a cathode to primary Li batteries. $\mathrm{CuF}_{2}$ typically displays a distinct plateau at $3.0 \mathrm{~V}$ (up to $1 \mathrm{Li}$ reaction number) and a subsequent sloped region down to $1 \mathrm{~V}$ (up to $2.1 \mathrm{Li}$ reaction number). From the relatively sharp XRD peaks assigned to Cu metal, Yamakawa et al. $^{58}$ concluded that the first formed $\mathrm{Cu}$ particles are large $(\sim 60 \mathrm{~nm})$, while these peaks become broad when the Li content exceeds 0.5 , indicating formation of smaller $\mathrm{Cu}$ particles $(9 \mathrm{~nm}$ based on Scherrer formula). High $\mathrm{Cu}$ mobility and electron conductivity are held responsible for the formation of unexpectedly large $\mathrm{Cu}$ particles at the early stage of reaction. These early $\mathrm{Cu}$ particles generate and grow mainly near the conductive network (e.g., activated carbon). The released $\mathrm{F}^{-}$ions are transported from the $\mathrm{CuF}_{2}-\mathrm{Cu}$ interface to the $\mathrm{CuF}_{2}$-electrolyte interface and therein react with more $\mathrm{Li}$ to form LiF. As the LiF layer grows a rather passivating coating is formed. This extra resistance for F-ion transport makes $\mathrm{Cu}$ start to nucleate within larger $\mathrm{CuF}_{2}$ particles, leading to the formation of $\mathrm{CuF}_{2} / \mathrm{Cu}$ nanodomains (Fig. 6a) and hence to particle pulverization (matrix destruction). However, the formation of $\mathrm{Cu}$ nanoparticles appears not to be helpful in significantly reducing the overpotential, since these $\mathrm{Cu}$ particles are surrounded initially by insulating $\mathrm{CuF}_{2}$ and then by LiF, and assembling into an electronic chain or network as in the case of $\mathrm{FeF}_{x}$ is difficult.

Recently, Wang et al. ${ }^{59}$ developed a novel strategy to fully utilize the $\mathrm{Cu}^{2+} / \mathrm{Cu}^{0}$ redox range and achieved the first application of $\mathrm{Cu}$-based fluoride in rechargeable $\mathrm{Li}$ batteries. The prepared solid solutions of $\mathrm{FeF}_{2}$ (tetragonal rutile) and of $\mathrm{CuF}_{2}$ (monoclinic distorted rutile) result in $\mathrm{Cu}_{1-x} \mathrm{Fe}_{x} \mathrm{~F}_{2}$ with a tetragonal rutile structure of a higher symmetry than the pure $\mathrm{CuF}_{2}$. $\mathrm{FeF}_{2}$ doping is also beneficial for the introduction of a percolating conductive network consisting of converted $\mathrm{Fe}$ nanoparticles in $\mathrm{Cu} / \mathrm{LiF}$ nanodomains. $\mathrm{Cu}_{1}-{ }_{x} \mathrm{Fe}_{x} \mathrm{~F}_{2}$ displays a two-stage lithiation process: a Cu-based conversion reaction (upper plateau at $\sim 2.9 \mathrm{~V}$ ) in a similar potential range as $\mathrm{CuF}_{2}$ and a Fe-based conversion reaction at a much higher potential $(\sim 2.2 \mathrm{~V})$ than $\mathrm{FeF}_{2}$ (Fig. 6b). The kinetic improvement also lies in the removal of the voltage dip observed in $\mathrm{FeF}_{2}$ and a reduction of the voltage hysteresis $\left(<150 \mathrm{mV}\right.$ for $\mathrm{Cu}^{2}$ ${ }^{+} / \mathrm{Cu}^{0}$ estimated by GITT). $\mathrm{Cu}_{0.5} \mathrm{Fe}_{0.5} \mathrm{~F}_{2}$ shows a capacity of 575 and $543 \mathrm{mAh} / \mathrm{g}$ during the first discharge and recharge processes, respectively, both close to the theoretical capacity $(549 \mathrm{mAh} / \mathrm{g})$ based on two-electron transfer. It indicates a full reoxidation of $\mathrm{Cu}$ in the delithiated cathode. The reconversion of $\mathrm{Cu}$ starts from a low potential and largely overlaps with the oxidation of Fe. This may be responsible for the regeneration of solid-solution rutile $\mathrm{Cu}_{1-x} \mathrm{Fe}_{x} \mathrm{~F}_{2}$ despite the higher disorder. During the first-half conversion, the scenario that as-formed nanostructured $\mathrm{FeF}_{2}$
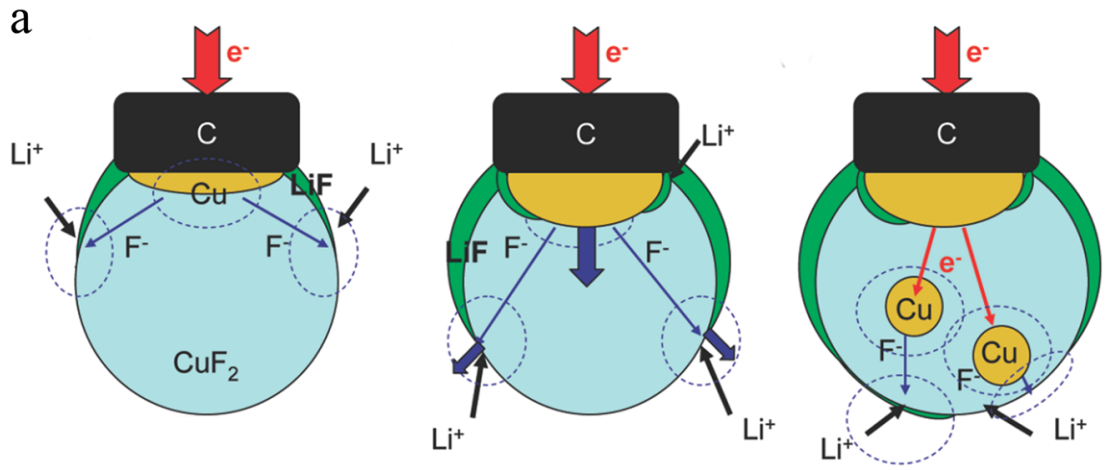

b

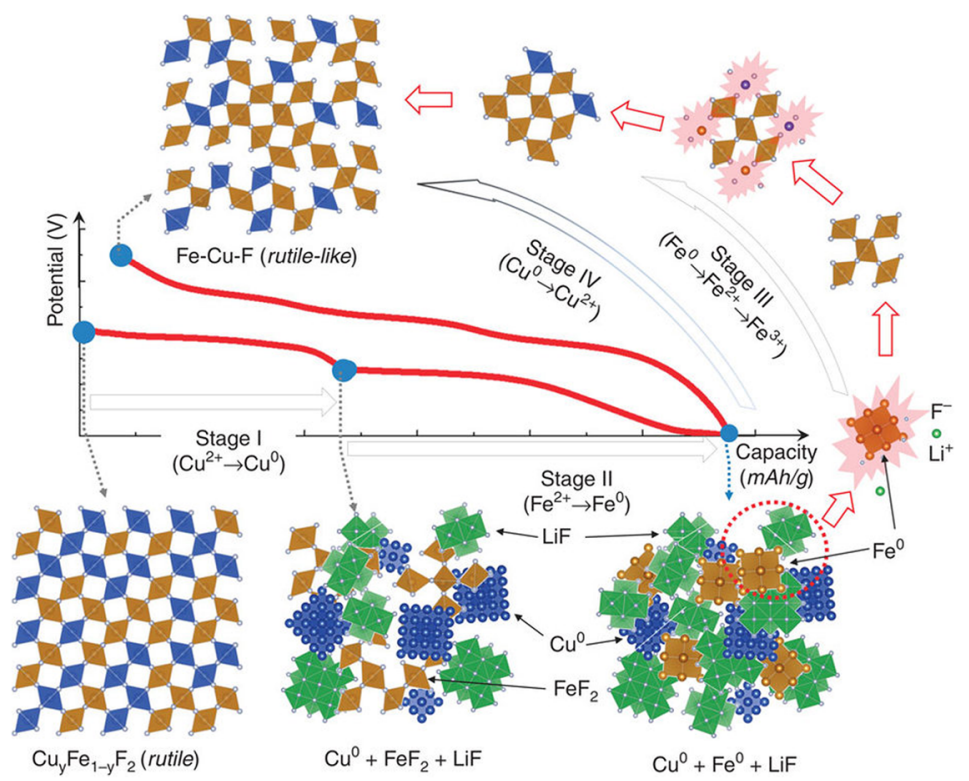

Fig. 6 a Scheme of potential reaction pathway of $\mathrm{CuF}_{2}$ during cycling (reproduced with permission from ref. ${ }^{58}$, copyright American Chemical Society 2009). b Scheme of potential reaction pathway of $\mathrm{Cu}_{1-x} \mathrm{Fe}_{x} \mathrm{~F}_{2}$ during cycling. The conversion reduction to $\mathrm{Cu}$ and Fe occurs sequentially during discharge (stages I and II). The following oxidation processes of Fe and Cu (stages III and IV) overlap during charge, enabling the reformation of rutile-like Cu-Fe-F phase but with disordering (reproduced from ref. ${ }^{59}$ ) 
intermediates are surrounded by metallic Cu likely accelerates the second-half conversion to metallic $\mathrm{Fe}$ due to the improved electron (from already formed conductive $\mathrm{Cu}$ nanodomains) and ion (from more $\mathrm{LiF} / \mathrm{FeF}_{2}$ interfaces) transport. The lattice disorder in $\mathrm{FeF}_{2}$ likely increases with down-sizing of $\mathrm{FeF}_{2}$ after first-half conversion, which is held responsible for the disappearance of voltage dip and higher discharge voltage during the initial second-half conversion. The small voltage hysteresis of $\mathrm{Cu}^{2+} / \mathrm{Cu}^{0}$ conversion is attributed to the low nucleation barrier for $\mathrm{Cu}$ fluoride formation/decomposition. This report emphasizes the advantage of a synergetic conversion system using multiple redox centers (mixed cations herein) in the same lattices. ${ }^{59}$

$\mathrm{BiF}_{3}$ is another highly active fluoride cathode characterized by direct conversion to metallic $\mathrm{Bi}$ and LiF. Although $\mathrm{Bi}$ is a relatively heavy element, its three-electron transfer and high theoretical potential of $3.21 \mathrm{~V}$ still provide a considerable energy density of $969 \mathrm{Wh} / \mathrm{kg}^{54}$ The major advantage of $\mathrm{BiF}_{3}$ lies in the extraordinarily high volumetric energy density of $8042 \mathrm{Wh} / \mathrm{L}$. Kinetic limitations and probably the dominance of a nonequilibrium reaction path results in that the discharge voltage equilibrated by GITT is still by $\sim 300 \mathrm{mV}$ lower than the theoretical value. The plausible O-doping strategy was also applied in Bi-based fluoride. ${ }^{55}$ Some oxyfluorides (e.g., $\mathrm{BiOF}$ and $\mathrm{BiO}_{0.5} \mathrm{~F}_{2}$ ) were successfully prepared. In contrast to $\mathrm{FeOF}$, formation of oxyfluoride $\mathrm{BiO}_{x} \mathrm{~F}_{3-2 \times}$ (rather than a two-phase mixture of $\mathrm{Bi}_{2} \mathrm{O}_{3}$ and $\mathrm{BiF}_{3}$ ) is achievable after electrochemical cycling. The conversion reaction occurs sequentially with the formation of $\mathrm{Bi}^{\circ}$, $\mathrm{LiF}$, and $\mathrm{Bi}_{2} \mathrm{O}_{3}$ at higher voltage and further reduction of $\mathrm{Bi}_{2} \mathrm{O}_{3}$ to $\mathrm{Li}_{2} \mathrm{O}$ and $\mathrm{Bi}^{\mathrm{O}}$ in the second plateau. The delithiation process is roughly reversed with the splitting of $\mathrm{Li}_{2} \mathrm{O}$ first and $\mathrm{LiF}$ later. For the $\mathrm{Bi}$ based fluoride, it was found that the carbonate electrolyte is not stable in the presence of Bi nanoparticles that are formed after the conversion, which induce the catalytic decomposition of solid electrolyte interface (SEI) layer at high voltage. ${ }^{60}$ This phenomenon causes the release of an O-containing species, which can diffuse into the subsurface of the fluoride structure and trigger the formation of oxyfluoride $\left(\mathrm{BiO}_{x} \mathrm{~F}_{3-2 x}\right)$. The portion of this in situ generated oxyfluoride increases with increasing cycle number. This result also indicates a novel electrochemical synthesis route to oxyfluoride electrode. So far, other fluorides based on $\mathrm{Mn}, \mathrm{Co}$, $\mathrm{Ni}$, and $\mathrm{Ti}$ are not promising as cathodes, since their conversion reactions are shifted to the anode voltage range. ${ }^{61-64}$ Strategies such as doping (NiO-doped $\mathrm{NiF}_{2}$ ), ion conductive coating (LiPONcoated $\left.\mathrm{CoF}_{2}\right)$, textured thin film architecture $\left(\mathrm{CoF}_{2}\right.$ thin film), or self-assembly of metallic conductive networks (for nanostructured $\mathrm{MnF}_{2}$ ) have not shown to be effective in improving the cathodic function. Making use of structural variations such as employing rutile $\left(\mathrm{LiMnF}_{4}\right)$ or spinel $\left(\mathrm{Li}_{2} \mathrm{NiF}_{4}\right)$ have also not led to an improvement of the capacity and its retention in the cathode voltage range. ${ }^{65,66}$ But some encouraging information can be gained from these investigations. For example, fluorination of Tibased oxide appears to be helpful in the reduction to metallic $\mathrm{Ti}^{\circ}$, which increases the electrochemical reversibility and enables facile splitting of $\mathrm{LiF}$ to form $\mathrm{TiF}_{3}{ }^{67}$ Reduction to the metallic state of $\mathrm{Ti}$ is unfeasible for oxides.

\section{CONVERSION SYSTEMS WITH PRIOR LIF SPLITTING}

Since most fluorides are Li-free, common Li-free anodes (e.g., graphite, $\mathrm{Si}$ ) cannot be used in the LIB framework. Similar to electrochemical splitting of $\mathrm{Li}_{2} \mathrm{O}_{x}$ and $\mathrm{Li}_{2} \mathrm{~S}$, LiF can also be split under the participation of transition metal, low-valence transition metal oxide or fluoride, enabling the construction of 'ion batteries'. ${ }^{68-70}$ Inspired by the decomposition products of $\mathrm{FeF}_{3}$, a pristine composite electrode consisting of nanostructured Fe and LiF was prepared. ${ }^{68,71}$ However, the Fe/LiF electrode failed to achieve the expected capacity owing to lattice mismatch and poor phase distribution. The conversion of $\mathrm{Fe} / \mathrm{LiF}$ to $\mathrm{FeF}_{3}$ requires multiple nucleation and phase transformation processes. The reversible capacity is limited to $300 \mathrm{mAh} / \mathrm{g}$ with large voltage polarization even if discharged to $1 \mathrm{~V}$ or below. Later, Kim et al. ${ }^{69}$ enhanced the oxidation state of the Fe-based component by using $\mathrm{FeF}_{2}$ precursor (instead of metallic $\mathrm{Fe}$ ) and achieved a better lattice matching with LiF at the cost of the capacity (Fig. 7a). LiF$\mathrm{FeF}_{2}$ provides a reversible capacity of around $200 \mathrm{mAh} / \mathrm{g}$ with negligible polarization with most capacity being located above $3 \mathrm{~V}$ (Fig. 7d). In the first cycle a remarkable structure reconstruction takes place that is responsible for the large overpotential during that cycle. After the first cycle formation of a trigonal defective $\mathrm{FeF}_{3}$-like phase is suggested to occur as a consequence of F-ion incorporation into $\mathrm{FeF}_{2}$. In the following cycle, a reversible phase evolution from trigonal $\mathrm{FeF}_{3}$ to tri-rutile $\mathrm{Li}_{x} \mathrm{FeF}_{3}$ was proposed to occur, similar to the (de)intercalation reaction of $\mathrm{FeF}_{3}$. In ref. ${ }^{69} \mathrm{a}$ full cell was constructed by pairing a $\mathrm{LiF}_{-} \mathrm{FeF}_{2}$ composite cathode with a carbon anode. The cycling stability of this $\mathrm{C}-\mathrm{LiF}_{-}-\mathrm{FeF}_{2}$ cell was found to be satisfactory with a reversible capacity of $165 \mathrm{mAh} / \mathrm{g}$ and discharge voltage range of $1.5-3 \mathrm{~V}$ at least during early cycling. Equally, we expect a good full-cell performance for a Li-free (oxy)fluoride cathode and a lithiated graphite anode. Different from the immiscible $\mathrm{LiF}_{-} \mathrm{FeF}_{2}$ system, $\mathrm{NaF}$ and $\mathrm{FeF}_{2}$ can form a solid-solution phase $\left(\mathrm{NaFeF}_{3}\right)$, which functions as insertion cathode for Na-ion batteries. ${ }^{72}$

In view of the advantage of oxyfluoride, more conductive $\mathrm{MO}$ ( $\mathrm{M}=\mathrm{Fe}, \mathrm{Mn}, \mathrm{Ni}, \mathrm{Co}$ ) precursors appear to enable the improvement of conversion kinetics when mixing or bonding with LiF. ${ }^{70,73-75}$ Most recently, Jung et al. ${ }^{70}$ developed a LiF-MnO conversion cathode with a dominant pseudocapacitive contribution (as high as $94 \%$ ). The unusual electrochemistry is ascribed to a surface conversion mechanism realized by decorating nano-sized LiF on monoxide surface, which can cause a fast $\mathrm{F}$ absorption by $\mathrm{MnO}$ surface once reaction initiates. The electrochemical splitting of LiF was confirmed by XPS (Fig. 7b, c), where Li 1s peak at $56 \mathrm{eV}$ disappears after first charge and recovers after following discharge. The binding energy of $F 1 s$ peak shifts from 685.3 to $686.0 \mathrm{eV}$ after charge and is also recoverable after discharge. The peak signal at $686.0 \mathrm{eV}$ stems from the formation of $\mathrm{Mn}-\mathrm{F}$ bonding in order to compensate for the charge when $\mathrm{Mn}$ is oxidized beyond $\mathrm{Mn}^{2+}$ (e.g., defective spinel-like $\mathrm{Mn}^{3+} \mathrm{O}-\mathrm{F}$ ). For both LiF$\mathrm{MnO}$ and LiF-FeO systems, the discharge capacity can exceed $240 \mathrm{mAh} / \mathrm{g}$ (Fig. 7e, f). Under a high current density of $5 \mathrm{~A} / \mathrm{g}$, LiF$\mathrm{MnO}$ can still deliver a reversible capacity of $110 \mathrm{mAh} / \mathrm{g}$ for at least 100 cycles, in agreement with a fast surface process. Note that in spite of the conversion, the way how this electrode functions looks like a surface storage rather than conventional conversion storage. It is pointed out in ref. ${ }^{76}$ that the stationary cathode function of this system is a special case of the job-sharing principle, ${ }^{77}$ according to which the $\mathrm{F}^{-}$-rich adsorption layer takes up the $\mathrm{Li}^{+}$ and the MnO the electron. The process does not work for the LiFFeO system, LiF-FeO likely alloys to form a "LiFeOF" single phase. ${ }^{78}$

\section{CHALLENGES AND PERSPECTIVES}

Solid-solid conversion reactions are typically accompanied by the breaking and forming of bonds with transition metal, and involve generation or annihilation as well as motion of multiphase interfaces. These features as well as the complexity of the reaction pathways are responsible for the voltage polarization and cycling problems. Previous reports have provided some insight into such questions and more detailed insight is expected by advanced characterization and simulation tools. Since conversion reactions in fluoride electrodes often result in poorly crystallized conversion products due to amorphization or nanosizing, routine tools such as XRD are not appropriate to obtain deeper information. Therefore, advanced tools including HRTEM, EELS, NMR, XAS, PDF, and TXM are to be explored for conversion processes. $9,15,16$ HRTEM only provides the contrast for the metallic phase and is not 
a



$\mathrm{FeF}_{3}$-like phase

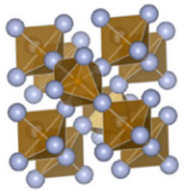

b

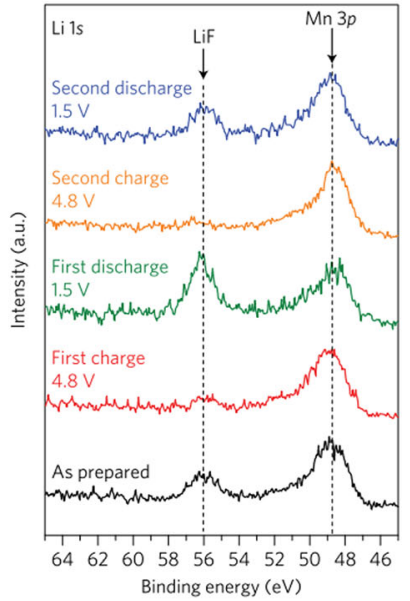

$\mathrm{c}$

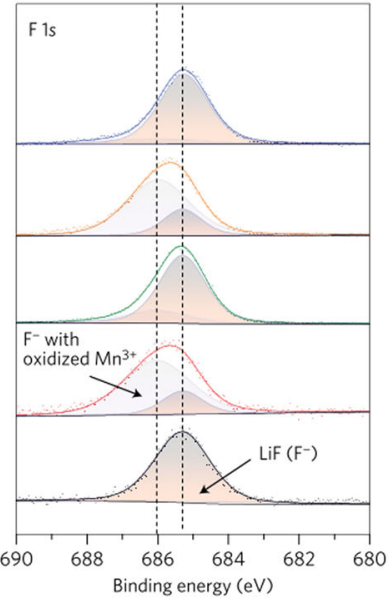

d

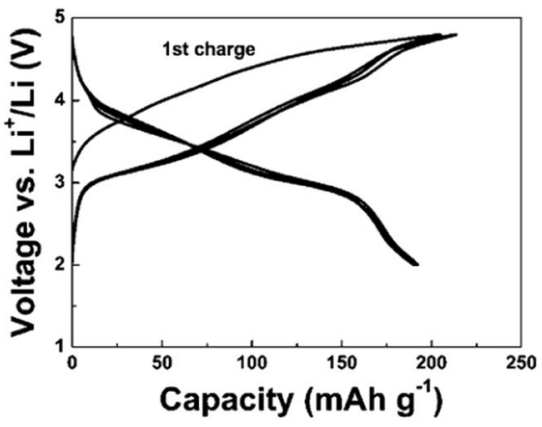

e

Li contents in LiF-MnO

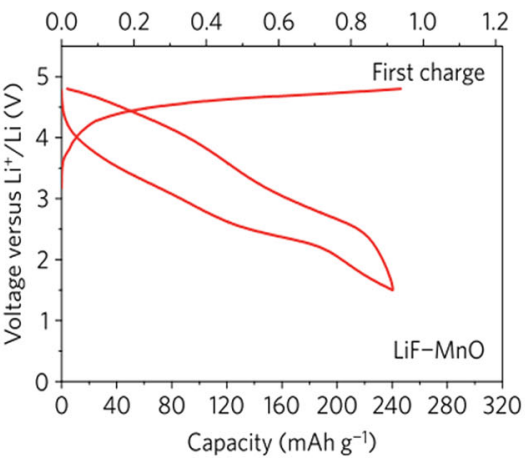

f

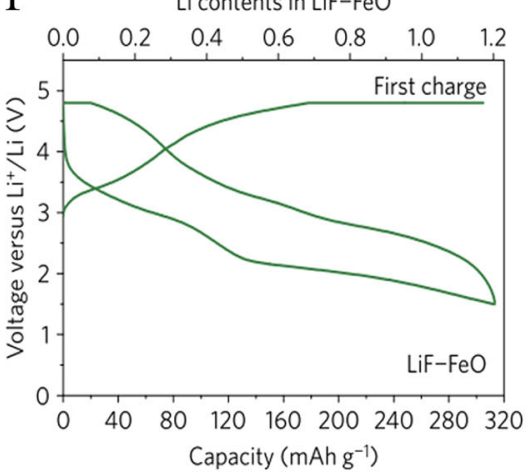

Fig. 7 a Scheme of reaction mechanism of $\mathrm{FeF}_{2}$-LiF composite (reproduced with permission from ref. ${ }^{69}$, copyright Elsevier 2012). b Ex situ XPS spectra of Li $1 s$ at different electrochemical stages. XPS peaks were normalized to the included Mn $3 p$ peaks in order to estimate Li content in electrode. c Ex situ XPS spectra of F $1 \mathrm{~s}$ at corresponding electrochemical stages. In order to avoid the interference by other $F$ source signals, polyacrylonitrile (PAN) was used as the binder and ethyl carbonate/dimethyl carbonate (EC/DMC; $\mathrm{v} / \mathrm{v}=1: 1)$ with $1 \mathrm{M}^{\mathrm{LiClO}} \mathrm{H}_{4}$ as electrolyte. Charge-discharge curves of (d) LiF-FeF ${ }_{2,}$ (e) LiF-MnO, and (f) LiF-FeO nanocomposites as cathodes for Li-ion batteries during the early cycling (reproduced with permission from ref. ${ }^{2}$, copyright Springer Nature 2017)

effective for the Li fluoride phase due to weak scattering of the light component elements. EELS is sensitive to light elements and enables high-resolution ( $1 \mathrm{~nm}$ scale) compositional images. PDF, XAS, and NMR are sensitive to short-range order and finer microstructural details of local structure, phase, and grain. TXM enables the visualization of electrochemically driven phase transformation even on a nanoscale.

The diffusion problems that are involved in the formation of various phases are not so problematic as it looks at a first glance. If the transport is very insufficient then automatically the composite formed will be a nanocomposite of very small scale. An important asset of the conversion reaction and of dealing with nanocomposites is the additional advantage to use interfacial storage which may be substantial when the interfacial density is high. A general recipe to make conversion reactions reversible has been given in ref. ${ }^{79}$ If one succeeds to go to the sub-nanoscale and to implement reactive "clusters" into a 1D current collector such as carbon fibers, one can expect a reversible situation, as recently realized for $\mathrm{MoS}_{2}$. In such cases, the differences of the various storage modes, intercalation, conversion and interfacial, are blurred and the full capacity range can be taken advantage of. The challenge here consists in the preparation and the use of such a recipe for fluorides has not yet succeeded.
The biggest challenge for fluorides is to find the solution to further lower the reaction overpotential and improve the conversion energy efficiency (EE). As shown in Fig. 8, the EE values are $70.7 \%$ and $74.1 \%$ for $\mathrm{FeF}_{3}$ and $\mathrm{FeOF}$, respectively, which are lower than those for $\mathrm{LiFePO}_{4}$ (93.9\%) and typical transition metal oxides (NMC, 95.8\%), but the energy densities of (oxy) fluorides are much higher, up to 1341.7 and $745.2 \mathrm{Wh} / \mathrm{kg}$ for $\mathrm{FeF}_{3}$ and $\mathrm{FeOF}$, respectively, at $100 \mathrm{~mA} / \mathrm{g}$. The manipulation of the topological structure and its channel geometry, as well as the design of external wiring network should be paid more attention into the future research, in order to enhance the transport properties of the effectively mixed conducting network. It is also recommendable to lay more emphasis on the surface defect chemistry of fluorides (especially of the metastable or framework phases), which may enable further optimization of spatial distribution of pristine phases, conversion products and conductive network components in electrode. A decisive tool is the defect chemistry of the involved phases including stoichiometric variations and doping. A promising way of improving the kinetics would also be (partially) bypassing the solid-solid conversion path and making use of liquid-solid conversion mechanisms. ${ }^{80,81}$ In this context it is worthwhile to address conversion reactions involving $\mathrm{Fe}$ and $\mathrm{LiBF}_{4}$ instead of $\mathrm{LiF}$, or to consider boron-based additives as $\mathrm{F}^{-}$receptors to dissociate $\mathrm{LiF}$. Exploring adapted electrolytes, 

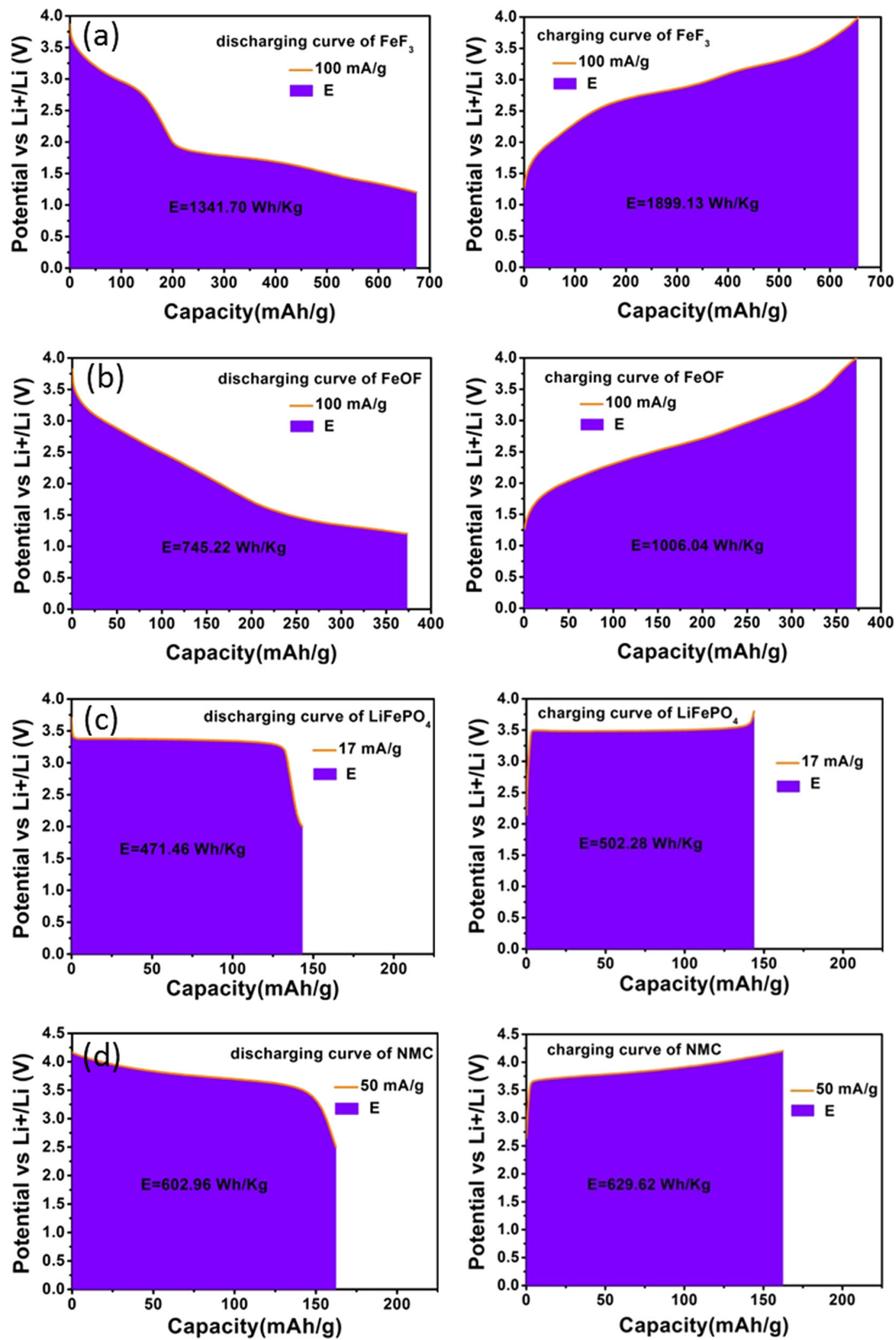


their discharge-charge curves. The energy efficiency values are $70.7 \%$ and $74.1 \%$ for $\mathrm{FeF}_{3}$ and FeOF, respectively, which are lower than those of typical $\mathrm{LiFePO}_{4}(93.9 \%)$ and NMC (95.8\%), although the energy densities of (oxy)fluorides are much higher and amount up to 1341.7 and $745.2 \mathrm{Wh} / \mathrm{kg}$ for $\mathrm{FeF}_{3}$ and FeOF, respectively, at $100 \mathrm{~mA} / \mathrm{g}$ 
additives, binders, and separators such that cathode dissolution effects as well as anode dendrite growth are suppressed is also necessary for commercializing energy storage fluoride materials in the future. ${ }^{82}$

The SEl effect on the electrochemistry of Fe-based (oxy)fluorides has been neglected for a long time. In fact, (oxy)fluorides show unique SEI features on the grain surfaces during cycling. The SEl consists of $\mathrm{LiF}, \mathrm{Fe}^{0}$, trapped $\mathrm{Fe}^{2+}$, and likely $\mathrm{FeO}$ on the outer surface. ${ }^{44,83}$ The SEl layer would grow and become thicker, and cause increased dissolution of $\mathrm{Fe}$ and accumulation of insulating LiF, connected with the loss of active species and larger Fe interparticle distance. Therefore, the reconversion step is seriously impeded on progressing cycling, resulting in capacity fading of fluoride materials as observed. The growth of LiF-rich SEI layers is not desired as it would slow down ionic and electronic transport. To address the problems of electrode dissolution and SEl passivation, an electrolyte based on a highconcentration LiFSI salt was recently developed to suppress cathode dissolution by in situ formation of Li-ion-permeable protection layer at the electrode surface. ${ }^{82}$ Most recently, ultrathin artificial SEl layers (e.g., $\mathrm{Al}_{2} \mathrm{O}_{3}$ and LiPON) were prepared by atomic layer deposition and reported to conformally coat fluoride particles and mitigate side reaction between fluoride and electrolyte. $^{84,85}$ Therefore, increased importance should be devoted to SEI issues in order to significantly improve the cycling stability of fluorides.

In summary, the strategies to electrochemically activate fluorides may include (1) building-block and defect-chemical variation in structure to achieve faster mass-charge transport, (2) construction of better effectively mixed conductive networks with nanoscale wiring, ${ }^{86}$ and (3) use of potential solid-liquid conversion (interface) reaction to bypass solid-solid conversion. Specifically for $\mathrm{FeF}_{3}$ with a reversible capacity of $500 \mathrm{mAh} / \mathrm{g}$, a loading of $6 \mathrm{mg} / \mathrm{cm}^{2}$ is required to achieve an areal capacity of $3 \mathrm{mAh} / \mathrm{cm}^{2}$ (the standard for commercial use). The main challenge of such thick electrodes with still satisfactory cycling and rate performance lies in mitigating contact degradation and volume effects of the total architecture.

\section{ACKNOWLEDGEMENTS}

This work was supported by National Key R\&D Program of China (2016YFB0901600), National Natural Science Foundation of China (51772313, 51372263), Key Research Program of Chinese Academy of Sciences (KGZD-EW-T06), and "Hundred Talents" Program of Chinese Academy of Sciences and"Thousand Talents"Program of Shanghai.

\section{AUTHOR CONTRIBUTIONS}

C.L. wrote the paper with input and suggestion from J.M., as well as with data processing from K.C. and X.Z.

\section{ADDITIONAL INFORMATION}

Competing interests: The authors declare no competing interests.

Publisher's note: Springer Nature remains neutral with regard to jurisdictional claims in published maps and institutional affiliations.

\section{REFERENCES}

1. Tikekar, M. D., Choudhury, S., Tu, Z. Y. \& Archer, L. A. Design principles for electrolytes and interfaces for stable lithium-metal batteries. Nat. Energy 1, 16114 (2016).

2. Bachman, J. C. et al. Inorganic solid-state electrolytes for lithium batteries mechanisms and properties governing ion conduction. Chem. Rev. 116, 140-162 (2016)

3. $\mathrm{Xu}, \mathrm{W}$. et al. Lithium metal anodes for rechargeable batteries. Energy Environ. Sci. 7, 513-537 (2014).
4. Bruce, P. G., Freunberger, S. A., Hardwick, L. J. \& Tarascon, J. M. Li-O 2 and Li-S batteries with high energy storage. Nat. Mater. 11, 19-29 (2012).

5. Conte, D. E. \& Pinna, N. A review on the application of iron(III) fluorides as positive electrodes for secondary cells. Mater. Renew. Sustain Energy 3, 37 (2014).

6. Cao, D. P., Yin, C. L., Zhang, J. C. \& Li, C. L. Bronze and pyrochlore type iron fluorides as cathode materials for Li/Na batteries (in Chinese). Chin. Sci. Bull. 62, 897-907 (2017).

7. Li, C. L., Gu, L., Tsukimoto, S., van Aken, P. A. \& Maier, J. Low-temperature ionicliquid-based synthesis of nanostructured iron-based fluoride cathodes for lithium batteries. Adv. Mater. 22, 3650-3654 (2010).

8. Li, C. L., Gu, L., Tong, J. W. \& Maier, J. Carbon nanotube wiring of electrodes for high-rate lithium batteries using an imidazolium-based ionic liquid precursor as dispersant and binder: a case study on iron fluoride nanoparticles. ACS Nano $\mathbf{5}$ 2930-2938 (2011).

9. Wang, F. et al. Conversion reaction mechanisms in lithium ion batteries study of the binary metal fluoride electrodes. J. Am. Chem. Soc. 133, 18828-18836 (2011).

10. Li, C. L., Gu, L. \& Maier, J. Enhancement of the Li conductivity in LiF by introducing glass/crystal interfaces. Adv. Funct. Mater. 22, 1145-1149 (2012).

11. Badway, F., Pereira, N., Cosandey, F. \& Amatucci, G. G. Carbon-metal fluoride nanocomposites: structure and electrochemistry of $\mathrm{FeF}_{3}-\mathrm{C}$. J. Electrochem. Soc. 150, A1209-A1218 (2003).

12. Pereira, N., Badway, F., Wartelsky, M., Gunn, S. \& Amatucci, G. G. Iron oxyfluorides as high capacity cathode materials for lithium batteries. J. Electrochem. Soc. 156, A407-A416 (2009).

13. Li, C. L., Gu, L., Tong, J. W., Tsukimoto, S. \& Maier, J. A mesoporous iron-based fluoride cathode of tunnel structure for rechargeable lithium batteries. Adv. Funct. Mater. 21, 1391-1397 (2011).

14. $\mathrm{Li}, \mathrm{C}$. L. et al. An $\mathrm{FeF}_{3} \cdot 0.5 \mathrm{H}_{2} \mathrm{O}$ polytype: a microporous framework compound with intersecting tunnels for $\mathrm{Li}$ and Na batteries. J. Am. Chem. Soc. 135, 11425-11428 (2013).

15. Yamakawa, N., Jiang, M., Key, B. \& Grey, C. P. Identifying the local structures formed during lithiation of the conversion material, iron fluoride, in a $\mathrm{Li}$ ion battery: a solid-state NMR X-ray diffraction and pair distribution function analysis study. J. Am. Chem. Soc. 131, 10525-10536 (2009).

16. Li, L. S. et al. Visualization of electrochemically driven solid-state phase transformations using operando hard X-ray spectro-imaging. Nat. Commun. 6, 6883 (2015).

17. Hu, J. L., Zhang, Y., Cao, D. P. \& Li, C. L. Dehydrating bronze iron fluoride as high capacity conversion cathode for lithium batteries. J. Mater. Chem. A 4, 16166-16174 (2016).

18. Arai, H., Okada, S., Sakurai, Y. \& Yamaki, J. Cathode performance and voltage estimation of metal trihalides. J. Power Sources 68, 716-719 (1997).

19. Badway, F., Cosandey, F., Pereira, N. \& Amatucci, G. G. Carbon metal fluoride nanocomposites: high capacity reversible metal fluoride conversion materials as rechargeable positive electrodes for $\mathrm{Li}$ batteries. J. Electrochem. Soc. 150, A1318-A1327 (2003).

20. Li, H., Balaya, P. \& Maier, J. Li-storage via heterogeneous reaction in selected binary metal fluorides and oxides. J. Electrochem. Soc. 151, A1878-A1885 (2004).

21. Doe, R. E., Persson, K. A., Meng, Y. S. \& Ceder, G. First-principles investigation of the $\mathrm{Li}-\mathrm{Fe}-\mathrm{F}$ phase diagram and equilibrium and nonequilibrium conversion reactions of iron fluorides with lithium. Chem. Mater. 20, 5274-5283 (2008).

22. Wang, F. et al. Tracking lithium transport and electrochemical reactions in nanoparticles. Nat. Commun. 3, 1201 (2012).

23. Ma, Y. \& Garofalini, S. H. Atomistic insights into the conversion reaction in iron fluoride: a dynamically adaptive force field approach. J. Am. Chem. Soc. 134, 8205-8211 (2012).

24. Ma, Y. \& Garofalini, S. H. Interplay between the ionic and electronic transport and its effects on the reaction pattern during the electrochemical conversion in an $\mathrm{FeF}_{2}$ nanoparticle. Phys. Chem. Chem. Phys. 16, 11690-11697 (2014).

25. Yu, P. F., Li, C. L. \& Guo, X. X. Sodium storage and pseudocapacitive charge in textured $\mathrm{Li}_{4} \mathrm{Ti}_{5} \mathrm{O}_{12}$ thin films. J. Phys. Chem. C. 118, 10616-10624 (2014).

26. Makimura, Y., Rougier, A. \& Tarascon, J. M. Pulsed laser deposited iron fluoride thin films for lithium-ion batteries. Appl. Surf. Sci. 252, 4587-4592 (2006).

27. Rangan, S. et al. Conversion reaction of $\mathrm{FeF}_{2}$ thin films upon exposure to atomic lithium. J. Phys. Chem. C. 116, 10498-10503 (2012).

28. Thorpe, R. et al. The solid state conversion reaction of epitaxial FeF $F_{2}(110)$ thin films with lithium studied by angle-resolved X-ray photoelectron spectroscopy. Phys. Chem. Chem. Phys. 17, 15218-15225 (2015).

29. Ko, J. K., Halajko, A., Parkinson, M. F. \& Amatucci, G. G. Electronic transport in lithiated iron and bismuth fluoride. J. Electrochem. Soc. 162, A149-A154 (2015).

30. Li, L. S. et al. Origins of large voltage hysteresis in high-energy-density metal fluoride lithium-ion battery conversion electrodes. J. Am. Chem. Soc. 138, 2838-2848 (2016).

31. Liu, P., Vajo, J. J., Wang, J. S., Li, W. \& Liu, J. Thermodynamics and kinetics of the Li/ $\mathrm{FeF}_{3}$ reaction by electrochemical analysis. J. Phys. Chem. C 116, 6467-6473 (2012). 
32. Zhang, W. et al. In situ electrochemical XAFS studies on an iron fluoride high capacity cathode material for rechargeable lithium batteries. J. Phys. Chem. C 117, 11498-11505 (2013).

33. Cui, Z. H. et al. Reaction pathway and wiring network dependent Li/Na storage of micro-sized conversion anode with mesoporosity and metallic conductivity. J. Mater. Chem. A 3, 509-514 (2015).

34. $\mathrm{He}, \mathrm{K}$. et al. Sodiation via heterogeneous disproportionation in $\mathrm{FeF}_{2}$ electrodes for sodium-ion batteries. ACS Nano 8, 7251-7259 (2014).

35. Chevrier, V. L., Hautier, G., Ong, S. P., Doe, R. E. \& Ceder, G. First-principles study of iron oxyfluorides and lithiation of FeOF. Phys. Rev. B 87, 094118 (2013).

36. Wiaderek, K. M. et al. Comprehensive insights into the structural and chemical changes in mixed-anion FeOF electrodes by using operando PDF and NMR spectroscopy. J. Am. Chem. Soc. 135, 4070-4078 (2013).

37. Ko, J. K. et al. Transport, phase reactions, and hysteresis of iron fluoride and oxyfluoride conversion electrode materials for lithium batteries. ACS Appl. Mater. Interfaces 6, 10858-10869 (2014).

38. Wiaderek, K. M. et al. Mesoscale effects in electrochemical conversion: coupling of chemistry to atomic- and nanoscale structure in iron-based electrodes. J. Am. Chem. Soc. 136, 6211-6214 (2014).

39. Zhou, $\mathrm{H}$. et al. Formation of iron oxyfluoride phase on the surface of nano- $\mathrm{Fe}_{3} \mathrm{O}_{4}$ conversion compound for electrochemical energy storage. J. Phys. Chem. Lett. 4, 3798-3805 (2013).

40. Zhou, $\mathrm{H}$. et al. Controlled formation of mixed nanoscale domains of high capacity $\mathrm{Fe}_{2} \mathrm{O}_{3}-\mathrm{FeF}_{3}$ conversion compounds by direct fluorination. ACS Nano 9, 2530-2539 (2015).

41. Zhang, W., Ma, L., Yue, H. J. \& Yang, Y. Synthesis and characterization of in situ $\mathrm{Fe}_{2} \mathrm{O}_{3}$-coated $\mathrm{FeF}_{3}$ cathode materials for rechargeable lithium batteries. J. Mater. Chem. 22, 24769-24775 (2012)

42. Kim, S. W. et al. Structure stabilization by mixed anions in oxyfluoride cathodes for high-energy lithium batteries. ACS Nano 9, 10076-10084 (2015).

43. Sina, M. et al. Structural phase transformation and Fe valence evolution in $\mathrm{FeO}_{x} \mathrm{~F}_{2}$ ${ }_{-x} / C$ nanocomposite electrodes during lithiation and de-lithiation processes. $J$. Mater. Chem. A 1, 11629-11640 (2013).

44. Sina, M., Pereira, N., Amatucci, G. G. \& Cosandey, F. Microstructural evolution of iron-oxyfluoride/carbon nanocomposites upon electrochemical cycling. J. Phys. Chem. C 120, 13375-13383 (2016).

45. Zhu, J. \& Deng, D. Wet-chemical synthesis of phase-pure FeOF nanorods as highcapacity cathodes for sodium-ion batteries. Angew. Chem. Int. Ed. 127, 3122-3126 (2015).

46. Zhou, Y. N. et al. $\mathrm{FeO}_{0.7} \mathrm{~F}_{1.3} / \mathrm{C}$ nanocomposite as a high-capacity cathode material for sodium-ion batteries. Adv. Funct. Mater. 25, 696-703 (2015).

47. Li, Z. S., Wang, B. Z., Li, C. L., Liu, J. J. \& Zhang, W. Q. Hydrogen-bonding-mediated structural stability and electrochemical performance in iron fluoride cathode materials. J. Mater. Chem. A 3, 16222-16228 (2015)

48. Dambournet, D. et al. Lithium insertion mechanism in iron-based oxyfluorides with anionic vacancies probed by PDF analysis. ChemistryOpen 4, 443-447 (2015).

49. Pohl, A. et al. Development of a water based process for stable conversion cathodes on the basis of $\mathrm{FeF}_{3}$. J. Power Sources 313, 213-222 (2016).

50. Conte, D. E. et al. Operando Mössbauer spectroscopy investigation of the electrochemical reaction with lithium in bronze-type $\mathrm{FeF}_{3} \cdot 0.33 \mathrm{H}_{2} \mathrm{O}$. J. Phys. Chem. $\mathrm{C}$ 120, 23933-23943 (2016).

51. Li, C. L., Mu, X. K., Van Aken, P. A. \& Maier, J. A high-capacity cathode for lithium batteries consisting of porous microspheres of highly amorphized iron fluoride densified from its open parent phase. Adv. Energy Mater. 3, 113-119 (2013).

52. Ali, G. et al. Probing the sodiation-desodiation reactions in nano-sized iron fluoride cathode. Electrochim. Acta 191, 307-316 (2016).

53. Ali, G. et al. An open-framework iron fluoride and reduced graphene oxide nanocomposite as a high-capacity cathode material for Na-ion batteries. J. Mater. Chem. A 3, 10258-10266 (2015).

54. Bervas, M. et al. Investigation of the lithiation and delithiation conversion mechanisms of bismuth fluoride nanocomposites. J. Electrochem. Soc. 153, A799-A808 (2006).

55. Bervas, M., Klein, L. C. \& Amatucci, G. G. Reversible conversion reactions with lithium in bismuth oxyfluoride nanocomposites. J. Electrochem. Soc. 153, A159-A170 (2006)

56. Badway, F. et al. Structure and electrochemistry of copper fluoride nanocomposites utilizing mixed conducting matrices. Chem. Mater. 19, 4129-4141 (2007).

57. Hua, $\mathrm{X}$. et al. Comprehensive study of the $\mathrm{CuF}_{2}$ conversion reaction mechanism in a lithium ion battery. J. Phys. Chem. C 118, 15169-15184 (2014).

58. Yamakawa, N., Jiang, M. \& Grey, C. P. Investigation of the conversion reaction mechanisms for binary copper(II) compounds by solid-state NMR spectroscopy and X-ray diffraction. Chem. Mater. 21, 3162-3176 (2009).

59. Wang, F. et al. Ternary metal fluorides as high-energy cathodes with low cycling hysteresis. Nat. Commun. 6, 6668 (2015).
60. Gmitter, A. J., Halajko, A., Sideris, P. J., Greenbaum, S. G. \& Amatucci, G. G. Subsurface diffusion of oxide electrolyte decomposition products in metal fluoride nanocomposite electrodes. Electrochim. Acta 88, 735-744 (2013).

61. Fu, Z. W. et al. Electrochemical reaction of lithium with cobalt fluoride thin film electrode. J. Electrochem. Soc. 152, E50-E55 (2005).

62. Lee, D. H. et al. Understanding improved electrochemical properties of NiOdoped $\mathrm{NiF}_{2} / \mathrm{C}$ composite conversion materials by $\mathrm{X}$-ray absorption spectroscopy and pair distribution function analysis. Phys. Chem. Chem. Phys. 16, 3095-3102 (2014).

63. Rui, K., Wen, Z. Y., Lu, Y., Jin, J. \& Shen, C. One-step solvothermal synthesis of nanostructured manganese fluoride as an anode for rechargeable lithium-ion batteries and insights into the conversion mechanism. Adv. Energy Mater. 5, 1401716 (2015).

64. Li, H., Richter, G. \& Maier, J. Reversible formation and decomposition of LiF clusters using transition metal fluorides as precursors and their application in rechargeable Li batteries. Adv. Mater. 15, 736-739 (2003).

65. Twu, N., Li, X., Moore, C. \& Ceder, G. Synthesis and lithiation mechanisms of dirutile and rutile $\mathrm{LiMnF}_{4}$ : two new conversion cathode materials. J. Electrochem. Soc. 160, A1944-A1951 (2013).

66. Lieser, G. et al. Sol-gel processing and electrochemical conversion of inverse spinel-type $\mathrm{Li}_{2} \mathrm{NiF}_{4}$. J. Electrochem. Soc. 162, A679-A686 (2015).

67. Dambournet, D. et al. Dual lithium insertion and conversion mechanisms in a titanium-based mixed-anion nanocomposite. J. Am. Chem. Soc. 133, 13240-13243 (2011).

68. Prakash, R. et al. A ferrocene-based carbon-iron lithium fluoride nanocomposite as a stable electrode material in lithium batteries. J. Mater. Chem. 20, 1871-1876 (2010).

69. Kim, S. W. et al. Energy storage in composites of a redox couple host and a lithium ion host. Nanotoday 7, 168-173 (2012).

70. Jung, S. K. et al. Lithium-free transition metal monoxides for positive electrodes in lithium-ion batteries. Nat. Energy 2, 16208 (2017).

71. Fan, X. L. et al. Pomegranate-structured conversion-reaction cathode with a built-in Li Source for high-energy Li-ion batteries. ACS Nano 10, 5567-5577 (2016).

72. Gocheva, I. D. et al. Mechanochemical synthesis of $\mathrm{NaMF}_{3}(\mathrm{M}=\mathrm{Fe}, \mathrm{Mn}, \mathrm{Ni})$ and their electrochemical properties as positive electrode materials for sodium batteries. J. Power Sources 187, 247-252 (2009).

73. Tomita, Y. et al. Synthesis and charge-discharge properties of LiF-NiO composite as a cathode material for Li-ion batteries. J. Power Sources 329, 406-411 (2016)

74. Zhang, L. T., Chen, G. H., Berg, E. J. \& Tarascon, J. M. Triggering the in situ electrochemical formation of high capacity cathode material from MnO. Adv. Energy Mater. 7, 1602200 (2017).

75. Dimov, N., Kitajou, A., Hori, H., Kobayashi, E. \& Okada, S. Electrochemical splitting of LiF: a new approach to lithium-ion battery materials. ECS Trans. 58, 87-99 (2014).

76. Chen, C. C. \& Maier, J. Decoupling electron and ion storage and the path from interfacial storage to artificial electrodes. Nat. Energy 3, 102-108 (2018).

77. Chen, C. C., Fu, L. J. \& Maier, J. Synergistic, ultrafast mass storage and removal in artificial mixed conductors. Nature 536, 159-164 (2016).

78. Kitajou, A., Kobayashi, E. \& Okada, S. Electrochemical performance of a novel cathode material "LiFeOF" for Li-ion batteries. Electrochemistry 83, 885-888 (2015).

79. Zhu, C. B., Mu, X. K., van Aken, P. A., Yu, Y. \& Maier, J. Single-layered ultrasmall nanoplates of $\mathrm{MoS}_{2}$ embedded in carbon nanofibers with excellent electrochemical performance for lithium and sodium storage. Angew. Chem. Int. Ed. 53, 2152-2156 (2014).

80. Matsui, T., Nakata, A., Hirai, T., Yamaki, J. \& Ogumi, Z. A reversible conversion reaction of metal and $\mathrm{BF}_{4}{ }^{-}$anions for the use in Li-ion batteries. J. Electrochem. Soc. 163, A660-A665 (2016)

81. Kumagae, K. et al. Improvement of cycling performance of $\mathrm{FeF}_{3}$-based lithium-ion battery by boron-based additives. J. Electrochem. Soc. 163, A1633-A1636 (2016).

82. $\mathrm{Gu}, \mathrm{W}$. T. et al. Lithium-iron fluoride battery with in situ surface protection. $A d v$. Funct. Mater. 26, 1507-1516 (2016).

83. Sina, M. et al. Investigation of SEl layer formation in conversion iron fluoride cathodes by combined STEM/EELS and XPS. J. Phys. Chem. C 119, 9762-9773 (2015).

84. Kim, S. et al. Improved performance in $\mathrm{FeF}_{2}$ conversion cathodes through use of a conductive 3D scaffold and $\mathrm{Al}_{2} \mathrm{O}_{3}$ ALD coating. Adv. Funct. Mater. 27, 1702783 (2017).

85. Lin, C. F. et al. Highly reversible conversion-type FeOF composite electrode with extended lithium insertion by atomic layer deposition LiPON protection. Chem. Mater. 29, 8780-8791 (2017)

86. Zhu, C. B., Usiskin, R. E., Yu, Y. \& Maier, J. The nanoscale circuitry of battery electrodes. Science 358, 1400 (2017). 
Open Access This article is licensed under a Creative Commons Attribution 4.0 International License, which permits use, sharing, adaptation, distribution and reproduction in any medium or format, as long as you give appropriate credit to the original author(s) and the source, provide a link to the Creative Commons license, and indicate if changes were made. The images or other third party material in this article are included in the article's Creative Commons license, unless indicated otherwise in a credit line to the material. If material is not included in the article's Creative Commons license and your intended use is not permitted by statutory regulation or exceeds the permitted use, you will need to obtain permission directly from the copyright holder. To view a copy of this license, visit http://creativecommons. org/licenses/by/4.0/.

(c) The Author(s) 2018 